University of Louisville

ThinkIR: The University of Louisville's Institutional Repository

$5-2013$

\title{
Examining the substrate specificity of factor XIIla towards peptide substrate modelsaC fibrin domains.
}

Jacob Bell

University of Louisville

Follow this and additional works at: https://ir.library.louisville.edu/honors

Part of the Chemistry Commons

\section{Recommended Citation}

Bell, Jacob, "Examining the substrate specificity of factor XIIla towards peptide substrate modelsaC fibrin domains." (2013). College of Arts \& Sciences Senior Honors Theses. Paper 5.

http://doi.org/10.18297/honors/5

This Senior Honors Thesis is brought to you for free and open access by the College of Arts \& Sciences at ThinkIR: The University of Louisville's Institutional Repository. It has been accepted for inclusion in College of Arts \& Sciences Senior Honors Theses by an authorized administrator of ThinkIR: The University of Louisville's Institutional Repository. This title appears here courtesy of the author, who has retained all other copyrights. For more information, please contact thinkir@louisville.edu. 
Examining the Substrate Specificity of Factor XIIIa towards Peptide Substrate Models and $\alpha \mathrm{C}$ Fibrin Domains

by

Jacob Bell

Submitted in partial fulfillment of the requirements for graduation summa cum laude and with Honors.

Department of Chemistry

University of Louisville

March 2013 


\section{$\underline{\text { Table of Contents }}$}

Abstract 2

I. Introduction 3

II. Specific Aims 11

III. Experimental Procedures 12

$\begin{array}{lll}\text { IV. Results } & 18\end{array}$

V. Discussion 29

VI. Conclusions 40

VII. Acknowledgements 41

VIII. Appendix A 42

IX. References 48 


\section{$\underline{\text { Abstract }}$}

In the blood coagulation cascade, Factor XIII (FXIII) is a zymogen that is activated by thrombin (IIa) and $\mathrm{Ca}^{2+}$. Activated FXIII (FXIIIa) functions as a transglutaminase in the final steps of the clotting cascade by forming covalent crosslinks between fibrin monomers at reactive glutamine residues. This forms a stable clot structure, secure from proteolytic degradation. To monitor FXIIIa substrate sequence specificity, the glutamine-containing peptide models $S$. aureus Fnb A (100-114), $\alpha_{2} \mathrm{AP}(\mathrm{Q} 4 \mathrm{P})$ (1-15) and K9 (1-10) were introduced to the enzyme in the presence of ${ }^{15} \mathrm{NH}_{4} \mathrm{Cl}$. Using MALDI-TOF MS and ${ }^{15} \mathrm{~N}$ HSQC NMR experiments, it was seen that $\alpha_{2} \mathrm{AP}(\mathrm{Q} 4 \mathrm{P})$ (1-15) and K9 (1-10) were viable FXIIIa substrates, having isotopic nitrogen incorporated in their side chain amide groups. However, S. aureus Fnb A (100-114) was not able to undergo this catalytic reaction because of an interfering side reaction with the labeled nitrogen. The substrate specificity appears to be the result of chemical environment provided by the residues immediately surrounding the reactive glutamine, with a focus on the hybridization of the side chain carbons. The $\alpha \mathrm{C}(233-425)$ domain of fibrin monomers was also analyzed as an intact FXIIIa substrate protein. The reactive $\mathrm{Q}^{328}$ residue of the protein was seen to undergo enzymatic transglutamination linearly with time using MALDI-TOF MS. $2 \mathrm{D}{ }^{15} \mathrm{~N}$ HSQC experiments displayed that $\mathrm{Q}^{328}$ was not the only reactive glutamine in the protein but rather one of two or three reactive glutamines. 


\section{Introduction}

Hemostasis is a vital physiological process that causes the cessation of blood loss from wounded vessels of the circulatory system. Without this integral response to injury, the body would not have the capability to quell bleeding while the vessel walls repair. In the dynamic process of hemostasis, there are two basic mechanisms at work, vasoconstriction and blood coagulation. The latter mechanism requires numerous enzymes working together to coordinate the formation of a fibrin protein clot that stops blood flow. As seen in Figure 1, the coagulation pathway is described as a cascade of regulated protein activations and may be initiated in two possible pathways. The extrinsic pathway comes into play in the response to injury, whereas the

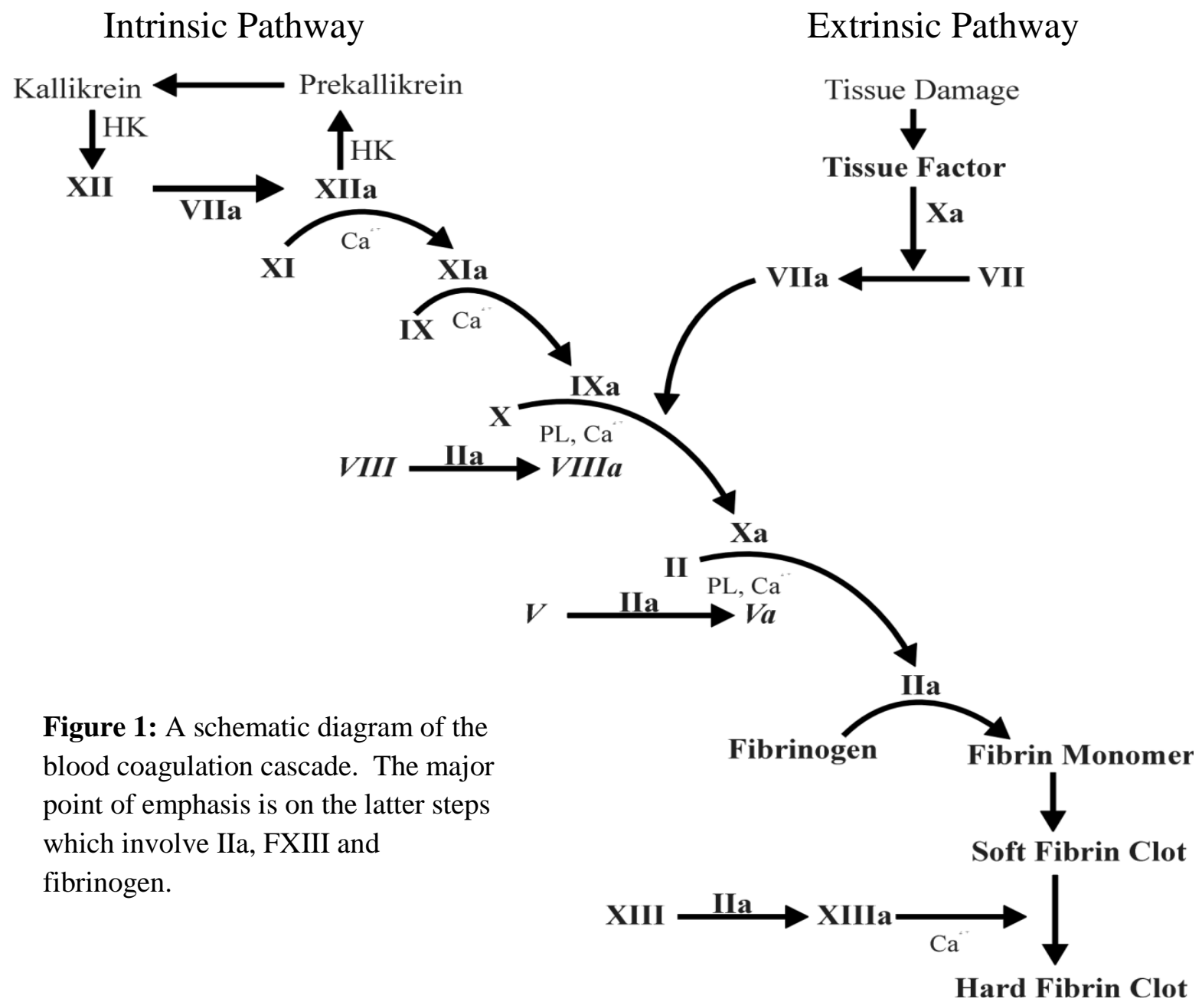


intrinsic pathway is initiated upon appearance of blood outside of the circulatory system. The two pathways later coalesce to a common enzymatic cascade that forms the fibrin clot. ${ }^{1}$

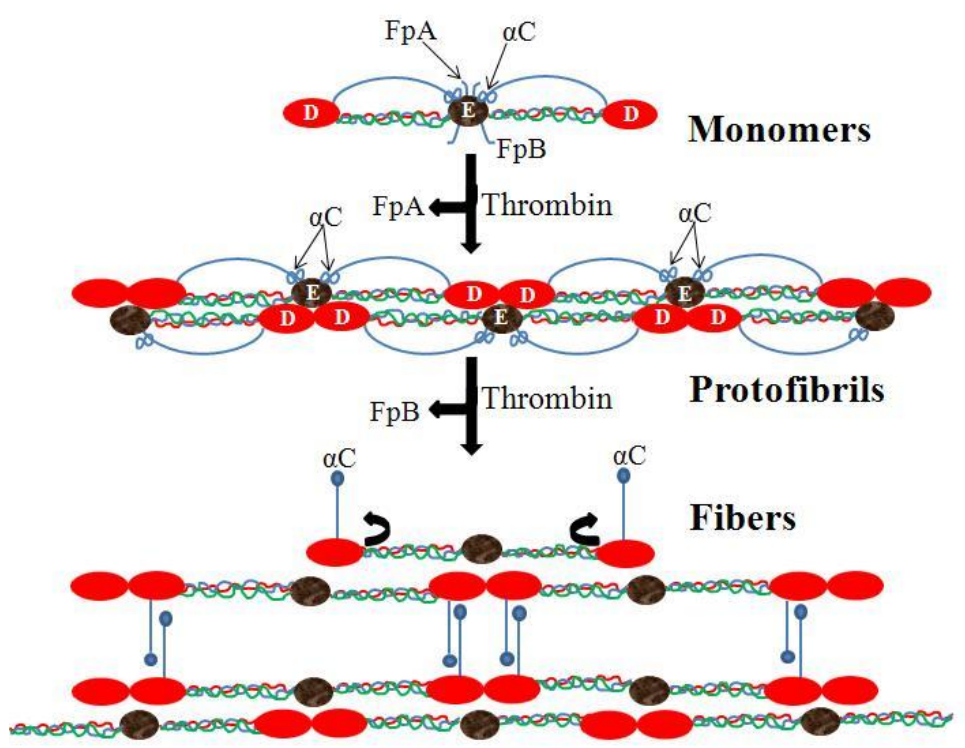

Figure 2: Illustration of actions of Ila on fibrin monomers and the aggregation of fibrin protofibers. Figure adapted from source. ${ }^{2}$
In the blood coagulation

cascade, the final steps of

clotting are achieved by

interactions among fibrinogen

(Fbg), thrombin (IIa) and

Factor XIII (FXIII). IIa is a

serine protease that cleaves $\mathrm{N}$ -

terminal portions of fibrinogen

chains, releasing

fibrinopeptides A and B (FpA

and $\mathrm{FpB}$ ) and converting Fbg

$(\mathrm{A} \alpha \mathrm{B} \beta \gamma)_{2}$ into fibrin $(\alpha \beta \gamma)_{2}$ monomers. The fibrin monomers non-covalently associate into protofibrils and then into fibers. This process is illustrated in Figure 2. The flexible $\alpha \mathrm{C}$ domains, residues 392-610, of the fibrin monomer are responsible for intermolecular interactions that later facilitate the strengthening of the fibrin architecture. ${ }^{2}$ The structure of a fibrin monomer and its $\alpha \mathrm{C}$ domain may be seen in Figure 3. As a consequence of the increase in fibrin concentration, the thrombin-mediated activation of FXIII is also enhanced. IIa, along with increased $\mathrm{Ca}^{2+}$ concentrations, function to activate the FXIII for the next process in the clotting cascade. $^{3}$

In blood plasma, FXIII is found as a heterotetramer with an attached activation peptide. There are two catalytic A-subunits and two inhibitory B-subunits; however, cellular FXIII is found only as a dimer of two A-subunits. IIa initially facilitates the cleavage of the activation 


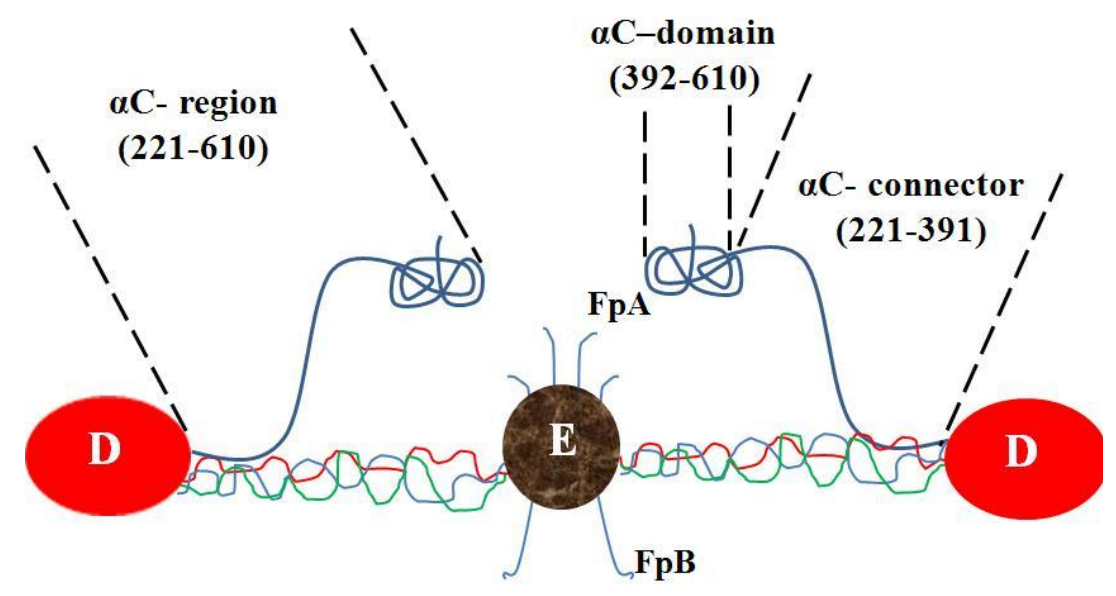

Fibrinogen

Figure 3: Illustration of the structure of a fibrinogen monomer, including fibrinopeptides and $\alpha \mathrm{C}$ domains. Figure modified from source. $^{2}$ peptide from the FXIII- $\mathrm{A}_{2}$, and then the $\mathrm{Ca}^{2+}$ allows the inhibitory FXIII- $\mathrm{B}_{2}$ to dissociate. The calcium ions are also needed to bind at a $\mathrm{Ca}^{2+}$ binding site near the catalytic core for enzymatic activity. This process fully creates active FXIII (FXIIIa) and can be

seen in Figure 4. FXIIIa initially crosslinks the $\gamma$-domains of the fibrin monomers. Then the enzyme can function to covalently crosslink the fibrin monomers at their $\alpha \mathrm{C}$ domains, strengthening the clotting structure from proteolytic degradation.
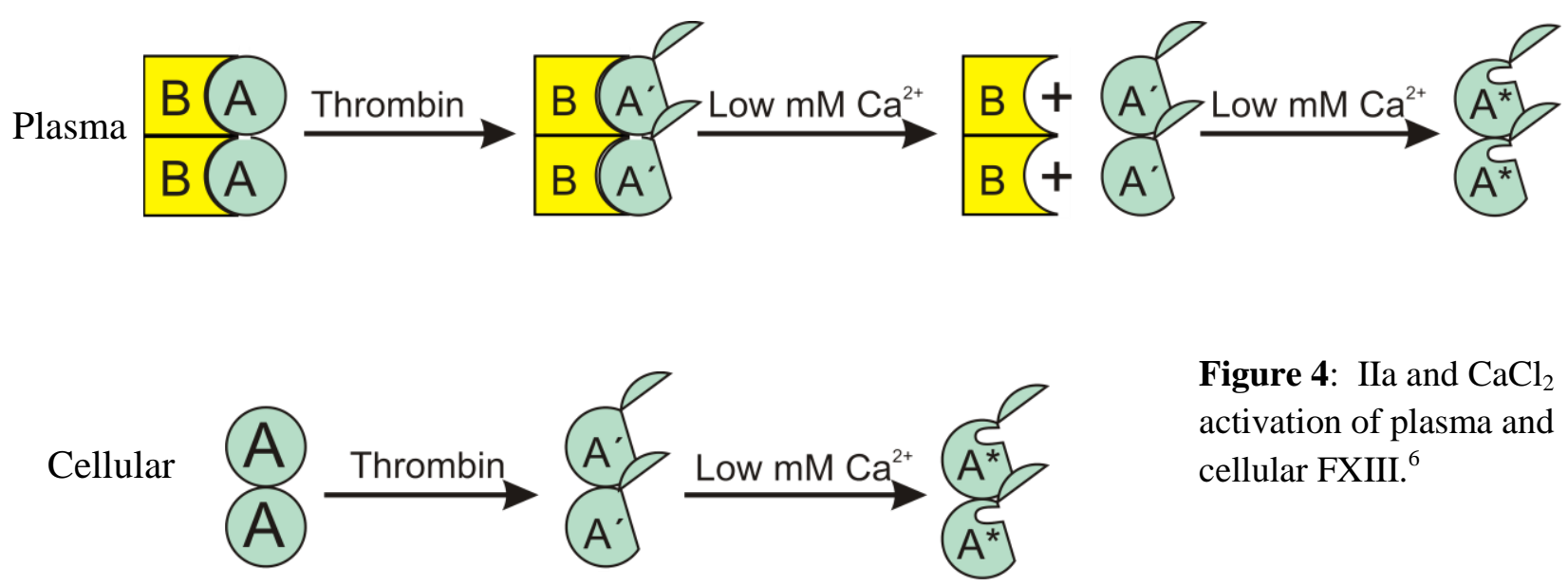

Cellular FXIII (FXIIIc) is found as a dimer of A subunits (FXIII-A $\mathrm{A}_{2}$ ) and is present in the cytoplasm of macrophages and platelets. FXIIIc is activated in a similar manner as FXIIIp and was the enzyme used in this study. ${ }^{2,4}$ FXIII may also be non-proteolytically activated by concentrations of $\mathrm{Ca}^{2+}$ beyond physiological conditions, in excess of $10 \mathrm{mM} .^{5}$ 
The crosslinking of fibrin monomers is achieved by FXIIIa's transglutaminase activity, which catalyzes an acyl transfer reaction between the side chain of a reactive glutamine (Q) and the side chain of normally a

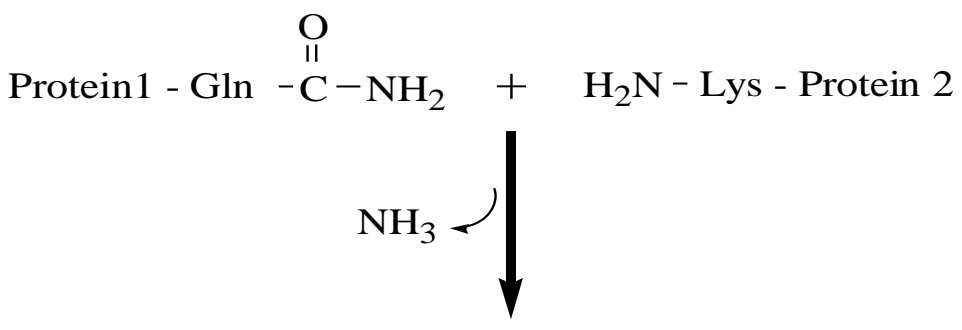

Protein1 - Gln - $\underset{\mathrm{O}}{\mathrm{C}}-\mathrm{NH}-$ Lys - Protein 2
Figure 5: The transglutamination between a glutamine and lysine facilitated by FXIIIa. FXIIIa forms an acyl enzyme intermediate, releasing ammonia. The lysine then attacks the intermediate and forms the isopeptide bond.

lysine $(\mathrm{K})$ residue. $^{7}$ The $\gamma$ -

carboxyamide of the glutamine residue serves as the acyl donor while the lysine residue functions as the acyl acceptor. A Q-containing substrate is initially bound in the enzyme's catalytic thiol-containing site and is then followed by the nucleophilic attack of a K-containing substrate's sidechain amine. This creates the isopeptide bond between the two residues and releases FXIII. ${ }^{7}$ A diagram of the transglutamination between glutamine and lysine may be seen in Figure 5. A number of physiological substrates for FXIIIa have been identified; however, a clear consensus sequence for the glutamine-containing substrate is not yet known. 
To analyze FXIIIa's reactivity and substrate sequence specificity, varying peptide models, approximately ten to fifteen residues in length, can be used. Because the exact source of FXIIIa's substrate specificity is not fully understood, the peptide sequences seen in Table 1 will provide insight into how varying amino acid sequences affect enzymatic activity. Each peptide model contains at least one reactive glutamine and has previously been shown to be an effective FXIIIa substrate. Staphylococcus aureus (S. aureus) is a pathogenic bacterium that contains a fibronectin binding protein A (Fnb A) that is able to be crosslinked into the human fibrin network. The Fnb A therefore allows the S. aureus to anchor on to its host cell. ${ }^{7,8}$ Another effective FXIIIa substrate is $\alpha_{2}$-antiplasmin ( $\left.\alpha_{2} \mathrm{AP}\right)$, a protein that prevents the activation of

\begin{tabular}{|c|c|}
\hline Table 1: Glutamine & 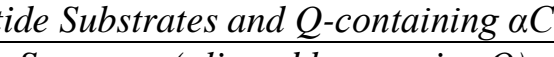 \\
\hline Substrate & Sequence (aligned by reactive $Q$ ) \\
\hline S. aureus Fnb A (100-114) & ${ }^{100} \mathrm{SGDQRQVDLIPKKAT} \mathrm{T}^{114}$ \\
\hline$\alpha_{2} \mathrm{AP}$ (native) (1-15) & ${ }^{1} \mathrm{NQEQVSPLTLLKLGN}{ }^{15}$ \\
\hline$\alpha_{2} \mathrm{AP}(\mathrm{Q} 4 \mathrm{P}) \quad(1-15)$ & ${ }^{1} \mathrm{NQEPVSPLTLLKLGN}{ }^{15}$ \\
\hline K9 (1-10) & ${ }^{1} \mathrm{LGPGQSKVIG}{ }^{10}$ \\
\hline$\alpha \mathrm{C}(325-342)$ & ${ }^{325} \mathrm{TGNQNPGSPRPGSTGTWNP}^{342}$ \\
\hline$\alpha \mathrm{C}(363-382)$ & ${ }^{363} \mathrm{STGQWHSESGSFRPSPGG}^{38}$ \\
\hline
\end{tabular}

plasmin from plasminogen. Plasmin is a protease that lyses existing clots. $\alpha_{2} \mathrm{AP}$ contains two potentially reactive glutamines in residues 1-15 that target FXIIIa's active binding site; however, only Q2 participates in vivo. FXIIIa forms a crosslink between Q2 of $\alpha_{2} \mathrm{AP}$ and K303 of the fibrin $\alpha$-chain. An $\alpha_{2} \mathrm{AP}$ mutant, Q4P, also is used because of its substitution of the peptide's second glutamine for a proline. This mutation would allow the enzymatic role of the second position glutamine to be probed. The peptide $\mathrm{K} 9(1-10)$ is also a peptide of interest, primarily because it only contains one glutamine residue. The K9 peptide is based on the reactive site of a larger FXIII substrate, $\beta$-casein. ${ }^{3}$

FXIIIa's substrate reactivity can be successfully modeled with the above mentioned sample peptides; however, to fully understand the scope of the enzyme's natural function, intact proteins 
and/or protein domains must also be studied. In previous work, it has been shown that the fibrinogen $\alpha \mathrm{C}$ region, residues 233-425, can interact and complex with FXIIIa, linking $\alpha \mathrm{C}$ glutamines and distant fibrinogen lysine residues. Therefore, the $\alpha \mathrm{C}$ domains are major anchors that hold the fibrin monomers together into a complex network. ${ }^{6}$ Also, recent studies suggest that interactions with $\alpha \mathrm{C}(233-425)$ may help promote FXIII activation. In the 192 residue $\alpha \mathrm{C}$ region, there are three glutamines that are potential targets of FXIII's transglutaminase activity: $\mathrm{Q}^{237}, \mathrm{Q}^{328}$ and $\mathrm{Q}^{366}$. The sequence of $\alpha \mathrm{C}(233-425)$ ma14y be seen below, the glutamines in red. $^{2,3,6}$
${ }^{233}{ }^{2}{ }^{2} M P Q{ }^{237}$ MRMELERPGGNEITRGGSTSYGTGSETESPRNPSSAGSWN SGSSGPGSTGNRNPGSSGTGGTATWKPGSSGPGSAGSWNSGSSGTGST GNQ $^{328}$ NPGSPRPGSTGTWNPGSSERGSAGHWTSESSVSGSTGQ ${ }^{366}$ WHSE $^{-}$ SGSFRPDSPGSGNARPNNPDWGTFEEVSGNVSPGTRREYHTEKLVTSKGD KELRT $^{425}$

From various proteolytic digests of $\alpha \mathrm{C}(233-425)$, distinct Q-containing fragments can be generated, which allows for the observation of each glutamine's reactivity by mass spectroscopy methods. Previous work in this area had suggested that $\mathrm{Q}^{237}$ is not a primary enzymatic focus, but the preference between $\mathrm{Q}^{328}$ and $\mathrm{Q}^{366}$ remained to be made. ${ }^{9}$ The sequences surrounding $\mathrm{Q}^{328}$ and $\mathrm{Q}^{366}$ can be seen in Table 1.

The reactive glutamines of the FXIII substrates may also be monitored by the use of the enzymatically labeling technique (ELT). With ELT, isotopically labeled ${ }^{15} \mathrm{NH}_{4} \mathrm{Cl}$ can act as a lysine mimic and utilize FXIIIa's transglutaminase activity to substitute the $\mathrm{Q}-\mathrm{NH}_{2}$ on the substrate with ${ }^{15} \mathrm{NH}_{2}$. The FXIII still promotes the creation of an acyl intermediate with the reactive glutamine, and without lysine, will undergo ${ }^{15} \mathrm{~N}$ exchange. This provides an invaluable technique in determining the affinity and location of the reactive glutamine in various Qcontaining peptide sequences because the isotopically labeled residues can be readily detected by ${ }^{15} \mathrm{~N}$ based-nuclear magnetic resonance (NMR) spectroscopy experiments. ${ }^{10}$ The ELT reaction 
may be seen below in Figure 6. The isotopic labeling also allows the labeled nitrogen exchange to be verified using matrix-assisted laser desorption ionization time of flight (MALDI-TOF) mass spectroscopy. A shift in $1 \mathrm{~m} / \mathrm{z}$ unit in the MS spectra of the FXIII-reacted peptides indicates an isotopic exchange, a difference between ${ }^{14} \mathrm{~N}$ and ${ }^{15} \mathrm{~N} .{ }^{3}$

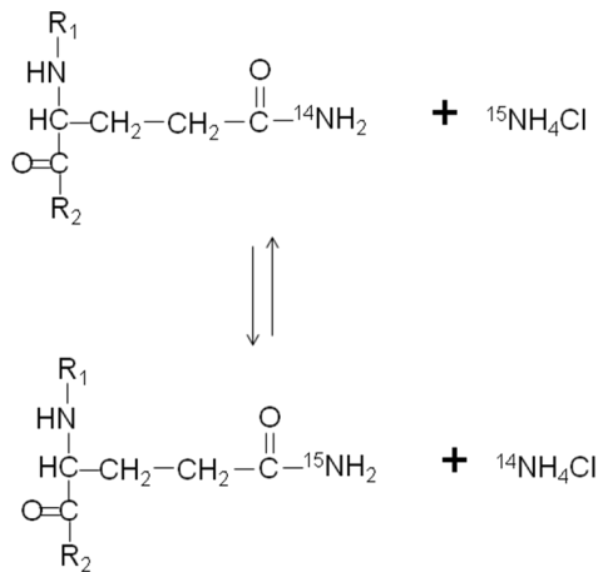

Figure 6: Enzymatic labeling of the $\gamma$-carboxyamide of reactive glutamine using a ${ }^{15} \mathrm{~N}$ labeled ammonium chloride. ${ }^{11}$

Another function of FXIIIa is its ability to facilitate the deamidation of a reactive glutamine to a glutamic acid (E) in the absence of a lysine-containing substrate or mimic. Studies have shown that when the substrate and enzyme are allowed to interact in an aqueous solution either an isopeptide bond between two of the same peptides is produced or the aforementioned deamidation reaction. The alteration of the Q to E can be monitored by a TOCSY (total correlation spectroscopy) NMR experiment. By analyzing S. aureus FnbA(100-114) in solution when it has and has not been introduced to FXIIIa should display two distinct spectra, one containing a $\mathrm{Q}$ and one containing an $\mathrm{E}$ resonance pattern. In general, the deamidation produces an upfield shift in the glutamine's $\mathrm{C} \alpha \mathrm{H}, \mathrm{C} \beta \mathrm{H}$ and $\mathrm{C} \gamma \mathrm{H}$ protons' chemical shifts. ${ }^{3}$

Monitoring the ability of FXIIIa to carry out a transglutamination in response to varying substrate sequences provides a better understanding of the enzyme's substrate specificity. This information would allow for a more detailed understanding of how FXIIIa forms covalent cross links and how to manipulate them. Additionally, the interactions between FXIIIa and the $\alpha \mathrm{C}$ 
domains of fibrin(ogen) are of integral importance in the stabilization of the clot structure. Understanding the preferential glutamine interactions between the two proteins would allow for more control when engineering new methods of altering blood coagulation. The ability to more specifically regulate the rate of formation and degradation of blood clots is a tool that would prove useful and advantageous in all branches of healthcare and research. 


\section{2. $\underline{\text { Specific Aims }}$}

The first aim of this research was to examine the substrate sequence specificity of FXIIIa by determining the amino acid sequence that provides the greatest transglutaminase reactivity from $S$. aureus $\mathrm{FbnA}, \alpha_{2} \mathrm{AP}, \alpha_{2} \mathrm{AP}(\mathrm{Q} 4 \mathrm{P})$ and $\mathrm{K} 9$ peptide models.

a) FXIIIa's transglutaminase activity was examined by the use of the enzymatic labeling technique with ${ }^{15} \mathrm{NH}_{4} \mathrm{Cl}$. This allowed the glutamine amide protons of the peptide models to be visualized using a ${ }^{15} \mathrm{~N}$ HSQC NMR experiment.

b) The isotopic reaction was further verified by monitoring the FXIIIa-mediated ${ }^{15} \mathrm{~N}$ exchange via MALDI-TOF MS analysis. A shift of 1 mass unit was detected if the transglutamination was successful.

The second aim of this research was to determine the reactivity of the three glutamine residues in the $\alpha \mathrm{C}$ region of fibrinogen towards FXIIIa.

a) In order to better monitor the enzyme's transglutaminase activity, a lysine mimic, glycineethyl ester, was crosslinked to $\alpha \mathrm{C}(233-425)$. This was developed into a timed kinetics assay. b) The reacted peptide was then proteolytically digested with chymotrypsin to produce distinct peptide fragments that allow the $\mathrm{Q}^{328}$ residue's individual activity to be monitored. Using MALDI-TOF MS, the rate with which the glycine ethyl ester is covalently crosslinked could be observed.

c) FXIIIa was used to cross link $\alpha \mathrm{C}(233-425)$ with another lysine mimic, dansylcadaverine (DC), in a kinetics assay. Because DC fluoresces under UV light, the crosslinked $\alpha \mathrm{C}+\mathrm{DC}$ was isolated with SDS-PAGE gel electrophoresis and verified by exposure to UV radiation.

d) FXIIIa's transglutaminase activity was examined by the use of the enzymatic labeling technique with ${ }^{15} \mathrm{~N}$-labeled ${ }^{15} \mathrm{NH}_{4} \mathrm{Cl}$. This allowed the glutamine amide protons of the peptide models to be visualized using a $1 \mathrm{D}$ and $2 \mathrm{D}{ }^{15} \mathrm{~N}$ HSQC NMR experiment. 


\section{Experimental Procedures}

\subsection{Peptide Substrate Model Sequences and Sources, including FXIII}

Peptide substrate models were synthesized and purified by New England Peptide,

Gardner, Massachusetts. Stock concentrations of the peptides were prepared in DI water. Their individual concentrations were determined by quantitative amino acid analysis (AAA Services, Boring, Oregon). The substrates analyzed include the following: S. aureus Fnb A (100-114), $\alpha_{2} \mathrm{AP}(1-15), \alpha_{2} \mathrm{AP}(\mathrm{Q} 4 \mathrm{P})$ (1-15) and K9 (1-10). The peptides' individual sequences may be seen in Table 2. Human cellular FXIII $\left(\mathrm{A}_{2}\right)$ was recombinantly expressed in Saccharomyces cerevisiea and generously provided by Dr. Paul Bishop of ZymoGenetics Inc., Seattle, Washington. Stock solutions of FXIII were prepared in DI water with their concentrations determined using an extinction coefficient of $\mathrm{E}^{1 \%}=14.9$.

\begin{tabular}{|l|l|}
\hline \multicolumn{2}{|c|}{ Table 2: Glutamine-Containing FXIIIa Peptide Substrates Models } \\
\hline Substrate & Sequence (aligned by reactive Q) \\
\hline S. aureus Fnb A (100-114) & ${ }^{100}$ SGDQRQVDLIPKKAT ${ }^{114}$ \\
\hline$\alpha_{2} \mathrm{AP}($ native) (1-15) & ${ }^{1}$ NQEQVSPLTLLKLGN ${ }^{15}$ \\
\hline$\alpha_{2} \mathrm{AP}(\mathrm{Q} 4 \mathrm{P})(1-15)$ & ${ }^{1} \mathrm{NQEPVSPLTLLKLGN}^{15}$ \\
\hline $\mathrm{K} 9(1-10)$ & ${ }^{1} \mathrm{LGPGQSKVIG}^{10}$ \\
\hline
\end{tabular}

\subsection{Non-proteolytic Activation of FXIII and ${ }^{15} \mathrm{~N}$ Labeling of Peptide Substrate Models}

The reaction was carried out in a $20 \mathrm{mM}$ borate buffer solution adjusted to $\mathrm{pH} 7$. This buffer condition supports FXIIIa activity and does not contribute any interfering protons during NMR analysis. The reaction design took advantage of FXIIIa's ability to be non-proteolytically activated by elevated concentrations of $\mathrm{Ca}^{2+}$. $400 \mathrm{nM}$ of FXIII $\mathrm{A}_{2}$ was combined with $50 \mathrm{mM}$ of $\mathrm{CaCl}_{2}$ in the borate buffer and allowed to incubate for approximately 15 minutes at $37^{\circ} \mathrm{C}$ in order to non-proteolytically activate the enzyme. Afterwards, $100 \mathrm{mM}$ of ${ }^{15} \mathrm{NH}_{4} \mathrm{Cl}$ was added along with $200 \mu \mathrm{M}$ of substrate peptide, S. aureus Fnb A (100-114), $\alpha_{2} \mathrm{AP}(1-15), \alpha_{2} \mathrm{AP}(\mathrm{Q} 4 \mathrm{P})(1-15)$ or K9 (1-10) in individual assays. The reaction mix was allowed to incubate for 30 minutes at room 
temperature before being prepared for analysis. For peptide samples in the absence of FXIIIa, the initial addition and incubation steps with FXIII were omitted, and the remaining components, borate buffer, $\mathrm{CaCl}_{2},{ }^{15} \mathrm{NH}_{4} \mathrm{Cl}$ and substrate peptides were combined. Comparing samples with and without the addition of FXIII will examine if the enzymatic reaction took place with respect to a nonenzymatically reacted control.

\subsection{MALDI-TOF MS Analysis of ${ }^{15}$ N-labeled Peptide Substrate Models}

The masses of the peptide substrates resulting from the FXIII and non-FXIII-mediated reactions with ${ }^{15} \mathrm{NH}_{4} \mathrm{Cl}$ were verified using an Applied Biosystems DE-Pro MALDI-TOF mass spectrometer. The peptides were placed into UV absorbing matrix using $1.0 \mu \mathrm{L}$ aliquots of each reaction sample mixed with $1.0 \mu \mathrm{L}$ of $\alpha$-cyano-4-hydroxycinnamic acid $(\alpha \mathrm{CHCA})$ matrix $\left(5 \mathrm{mg} / \mathrm{mL} \alpha \mathrm{CHCA}\right.$ in a $1: 1: 1$ ratio of $0.1 \%$ TFA, ethanol and acetonitrile) ${ }^{3} 0.5 \mu \mathrm{L}$ of matrixsample mix were spotted in triplicate on a 100-well stainless steel MALDI plate and dried using a speed-vacuum. The analysis was performed scanning the $m / z$ range from 800 to $4000 \mathrm{Da}$ with the instrument in positive reflector mode.

\subsection{Solution ${ }^{15}$ N HSQC NMR Studies}

The ${ }^{15} \mathrm{~N}$ exchange seen by the peptide substrate models and $\alpha \mathrm{C}(233-425)$ in the presence of FXIIIa was analyzed using a ${ }^{15} \mathrm{~N}$ heteronuclear single quantum coherence (HSQC) NMRbased experiment. The short acquisition time for 1D HSQC experiments allows the reaction's progress to be measured as a function of time. The $400 \mu \mathrm{l} \mathrm{NMR} \mathrm{sample} \mathrm{contained} \mathrm{a} 10 \%$ by volume amount of $\mathrm{D}_{2} \mathrm{O}$. This addition serves as an internal standard for the deuterium lock on the NMR. NMR samples were loaded into Shigemi NMR tubes. Each experiment was performed using an initial water suppression experiment. The parameters for each $1 \mathrm{D}{ }^{15} \mathrm{~N}$ HSQC experiment were $\mathrm{nt}=32, \mathrm{np}=4096$ and $\mathrm{sw} \approx 10,000$. The parameters for each $2 \mathrm{D}{ }^{15} \mathrm{~N}$ HSQC experiment were $n t=32, \mathrm{np}=4096, \mathrm{sw}=11,574, \mathrm{sw} 1=1944.3, \mathrm{bs}=64, \mathrm{ni}=8$. The 
parameters for each 2D TOCSY experiment were $\mathrm{nt}=32, \mathrm{np}=4096, \mathrm{sw}=7022.5, \mathrm{sw} 1=7022.5$, $\mathrm{ni}=256$ and arrayed phasing. ( $\mathrm{nt}=$ number of transients, $\mathrm{np}=$ number of points, $\mathrm{sw}=$ sweep width, ni=number of increments) NMR experiments were performed on a Varian $700 \mathrm{MHz}$ spectrometer equipped with z-axis pulse field gradients using a triple resonance probe. All experiments were conducted at $25^{\circ} \mathrm{C}$, with chemical shifts being referenced to the solvent, $\mathrm{H}_{2} \mathrm{O}$.

\section{4 aC Expression, Purification}

The $\alpha \mathrm{C}(233-425)$ protein was expressed using a glutathione-S-transferase (GST)-tagged recombinant $\alpha \mathrm{C}(233-425)$ plasmid DNA, generously provided by Dr. Helen Philippou and Dr. Robert A.S. Ariëns from the University of Leeds. The protein was expressed using an Escherichia coli BL21 Gold DE3 cell line in three separate 4 L cultures. IPTG was added to each culture to initiate the expression of the $\alpha \mathrm{C}$ protein of interest.The cultures were centrifuged, allowing the $E$. coli cells to be isolated and washed. The cells were lysed open and a cell extract was prepared. A protein-based solution was isolated from the cell extract. The $\alpha \mathrm{C}(233-425)$ was purified by using GST-affinity chromatography on an ÄKTAprime fast protein liquid chromatography (FPLC) instrument. The affinity column contains resin beads that selectively bind the GST, allowing the GST-protein to be isolated from the other biological compounds in the cell-protein solution that elute off the column. The GST tag was removed from the $\alpha \mathrm{C}(233-$ 425) with the use of a PreScission Protease digest while bound to the column, allowing the protein of interest to be eluted in 1x phosphate buffered saline (PBS) (137 mM NaCl, $2.7 \mathrm{mM}$ $\mathrm{KCl}, 10 \mathrm{mM} \mathrm{Na} 2 \mathrm{HPO}_{4}, 2 \mathrm{mM} \mathrm{KH} \mathrm{PO}_{4}$ ). The remaining cleaved GST was eluted off the column with elution buffer containing $50 \mathrm{mM}$ Tris- $\mathrm{HCl}, 20 \mathrm{mM}$ reduced glutathione, $1 \mathrm{mM}$ DTT at $\mathrm{pH}$ 8.0. The purification method was modeled after the GE Healthcare recommended method, which is where the protease and chromatography columns were purchased. ${ }^{9}$ 


\section{5 $\alpha \mathrm{C}$ Crosslinking with Dansylcadaverine Observed by SDS-PAGE Analysis}

The purity of the expressed $\alpha \mathrm{C}(233-425)$ 's purity was assessed and confirmed by the use of sodium dodecyl sulfate polyacrylamide gel electrophoresis (SDS-PAGE). This method was also used to verify that the molecular weight of $\alpha \mathrm{C}(233-425)$ was within the estimated range. The ability of the protein to be a FXIIIa substrate was assessed by enzymatically crosslinking the $\alpha \mathrm{C}$ protein's reactive glutamines with a lysine mimic, dansylcadaverine (DC), which fluoresces under UV light. This reaction is made possible by FXIIIa transglutaminase ability. $1.12 \mu \mathrm{M}$ of FXIII, $0.010 \mu \mathrm{M}$ IIa, $5 \mathrm{mM} \mathrm{CaCl}_{2}$ were combined in tris-acetate buffer $(100 \mathrm{mM}$ tris-acetate, 150 $\mathrm{mM} \mathrm{NaCl}, 0.1 \% \mathrm{PEG}_{8000}, \mathrm{pH} 7.4$ ) and allowed to incubate for 15 minutes at $37^{\circ} \mathrm{C}$ to activate the FXIII. Afterwards, $1.0 \mathrm{mM} \mathrm{DC}$ and $7.9 \mu \mathrm{M} \alpha \mathrm{C}(233-425)$ were added which initiated the reaction. Aliquots of the reaction mix were taken and quenched with a solution of $10 \% \beta$ mercaptoethanol and 2\% SDS at times points of $0,15,30$ and 45 minutes in order to monitor the progress of the transglutamination. The reacted samples were then analyzed using SDS-PAGE under non-reducing conditions. Samples were run on a 15\% acrylamide gel, visualized under UV light and then stained with Coomassie Blue.

\section{6 aC Transglutamination with Glycine Ethyl Ester Assay}

For this assay, the expressed $\alpha \mathrm{C}(233-425)$ was enzymatically crosslinked with the lysinemimic, glycine ethyl ester (GEE). As before, the reaction was quenched at defined time points to monitor the progression of the transglutamination. In tris-acetate buffer, $264 \mathrm{nM} \mathrm{FXIII,} 8.4 \mathrm{U} / \mathrm{ml}$ IIa, $4 \mathrm{mM} \mathrm{CaCl} 2$ and $17 \mathrm{mM} \mathrm{GEE}$ were combined and allowed to incubate for 10 minutes at $37^{\circ} \mathrm{C}$. After the incubation period, the IIa was quenched with $164 \mathrm{nM}$ PPACK, which is an active site inhibitor of the enzyme. Following a brief incubation time with the PPACK, $17 \mu \mathrm{M}$ of the expressed $\alpha \mathrm{C}$ was added to the reaction along with an additional $7 \mathrm{mM}$ of $\mathrm{CaCl}_{2}$, to bring the total $\mathrm{CaCl}_{2}$ concentration to $11 \mathrm{mM}$. Due to the phosphates present in the $1 \mathrm{x}$ PBS the $\alpha \mathrm{C}$ 
was eluted in, additional $\mathrm{CaCl}_{2}$ was added to account for the precipitation of the $\mathrm{Ca}^{2+}$ and the phosphates. The resulting free $\mathrm{Ca}^{2+}$ concentration was then approximately $4 \mathrm{mM}$. This added $\mathrm{Ca}^{2+}$ insures the continued activity of the FXIIIa. Reactions were quenched with a $10.6 \mathrm{mM}$ concentration of EDTA, a calcium ion scavenger.

\section{7 aC Transglutamination with GEE Assay, Chymotrypsin Digest, and MS Analysis}

After the $\alpha \mathrm{C}(233-425)-\mathrm{GEE}$ reaction samples were quenched with EDTA, they were proteolytically digested with chymotrypsin which selectively cleaves $\alpha \mathrm{C}$ after arginine and lysine residues. A chymotrypsin digest is used because the $\alpha \mathrm{C}$ protein is rather large to use for MALDI-TOF MS analysis. The smaller protein fragments can be more accurately detected and allow specific glutamines to be evaluated. Because the digest selectively produces a $\mathrm{Q}^{328}$ containing fragment, the protease allowed the reaction at this reactive glutamine to be specifically analyzed. Each digest took place in a volume of $13.1 \mu 1$, with $6 \mu$ of the reaction mix, $6 \mu$ of chymotrypsin buffer (100 mM tris- $\left.\mathrm{HCl}, 10 \mathrm{mM} \mathrm{CaCl}_{2}, \mathrm{pH} 7.4\right)$ and $1.1 \mu \mathrm{l}$ of 25 $\mathrm{mg} / \mathrm{ml}$ chymotrypsin in $1 \mathrm{mM} \mathrm{HCl}$. The digest was allowed to proceed for 30 minutes and was then followed by a quench with $6 \mu$ of 5\% TFA. After the quench, the samples were then prepared for MALDI-TOF MS analysis. Because the excess salts can interfere with MALDI-MS analysis, the digested samples were subjected to $\mathrm{C}_{18}$ zip tipping (Millipore) prior to being combined with the $\alpha \mathrm{CHCA}$ matrix and plated.

\subsection{Non-proteolytic Activation of FXIII and ${ }^{15} \mathrm{~N}$ Labeling of $\alpha \mathrm{C}(233-425)$}

The activation was carried out in a $20 \mathrm{mM}$ borate buffer solution adjusted to $\mathrm{pH} 7$. FXIII was nonenzymatically activated with elevated $\mathrm{Ca}^{2+}$ concentrations in this assay. 400nM of FXIII was combined with $50 \mathrm{mM}$ of $\mathrm{CaCl}_{2}$ in the borate buffer and allowed to incubate for approximately 15 minutes at $37^{\circ} \mathrm{C}$. Afterwards, $100 \mathrm{mM}$ of ${ }^{15} \mathrm{NH}_{4} \mathrm{Cl}$ and $10 \mathrm{mM}$ of additional $\mathrm{CaCl}_{2}$, to account for phosphates, was added along with $20 \mu \mathrm{M}$ of $\alpha \mathrm{C}(233-425)$ in $1 \mathrm{x}$ PBS. The 
reaction mix was allowed to incubate for 45 minutes at room temperature before being prepared to be analyzed. 1D and 2D ${ }^{15} \mathrm{~N}$ HSQC NMR experiments were conducted as with the peptide substrate models. 


\section{Results}

The substrate specificity of FXIIIa was analyzed with both peptide substrate models and the intact $\alpha \mathrm{C}(233-425)$ domain protein. The results from the different biochemical techniques offered insights into the function and specificity of this integral protein in the blood coagulation cascade.

\subsection{MALDI-TOF MS Analysis of FXIIIa ${ }^{15} \mathrm{~N}$-exchange with Substrate Peptide Models}

This assay proved to be a valuable tool in evaluating the extent to which FXIIIa mediated the isotopic ${ }^{15} \mathrm{~N}$ exchange at reactive glutamine residues of varying peptide sequences. The difference in 1 mass unit $(\mathrm{m} / \mathrm{z})$ between the unlabeled $\left({ }^{14} \mathrm{~N}\right)$ and any enzymatically reacted $\left({ }^{15} \mathrm{~N}\right)$ peptide would confirm that FXIIIa's transglutaminase reaction had occurred. Three different substrate peptides, S. aureus FnbA (100-114), $\alpha_{2} \mathrm{AP}(\mathrm{Q} 4 \mathrm{P})$ (1-15) and K9 (1-10), were exposed to ${ }^{15} \mathrm{NH}_{4}$ in the presence and absence of FXIIIa. The isotopic labeling assay provided insight into FXIIIa's substrate sequence preference.
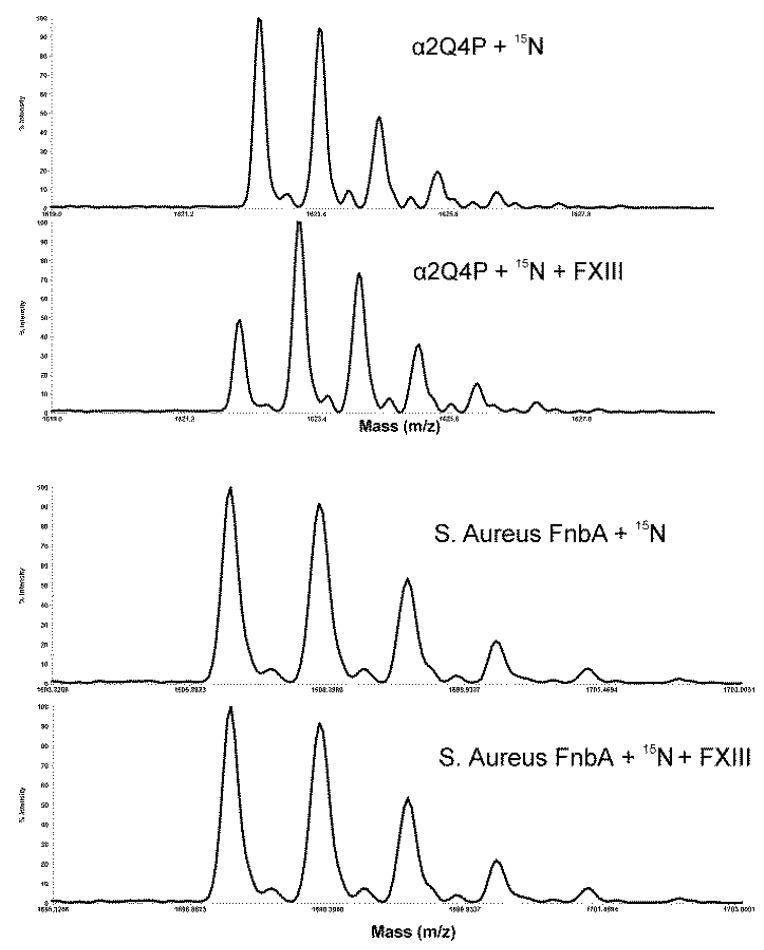

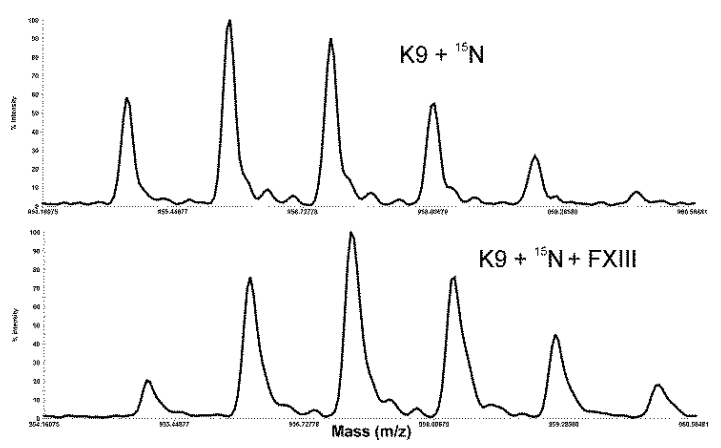

Figure 7: MALDI-TOF MS spectra of substrate models exchanged with ${ }^{15} \mathrm{~N}$ in the presence and absence of FXIIIa. The upper panel of each pair displays the nonenzymatic product, while the lower panels display the enzymatically mediated products. Molecular Weight: S. aureus FnbA(100-114): 1697 $\mathrm{g} / \mathrm{mol}$; $\alpha 2 \mathrm{APQ} 4 \mathrm{P}(1-15): 1622 \mathrm{~g} / \mathrm{mol}$; K9(110): $954.6 \mathrm{~g} / \mathrm{mol}$. 
The results of this experiment revealed the anticipated enzymatic behavior of FXIIIa on $\alpha_{2} \mathrm{AP}(\mathrm{Q} 4 \mathrm{P})$ (1-15) and K9 (1-10) substrates. The peptides appear in the MALDI-TOF spectra as a cluster of peaks, or a centroid, which result from the natural isotopic abundances of the atoms in the peptides. As seen in Figure 7, there is a clear shift in one peptide mass $(\mathrm{m} / \mathrm{z})$ unit when comparing the mass centroids with and without the addition of FXIIIa. The interesting substrate in this group was the S. Aureus FnbA (100-114); it displayed no mass shift. This absence suggests that the expected amide exchange at the reactive Q residue was unsuccessful in both catalytic and non-catalytic environments.

\section{2 ${ }^{15} \mathrm{~N}$ HSQC NMR Analysis of FXIIIa ${ }^{15} \mathrm{~N}$-exchange with Substrate Peptide Models}

This ${ }^{15} \mathrm{~N}$ HSQC NMR based approach was used to monitor FXIIIa's transglutaminase activity on Q-containing substrate peptides. The ${ }^{15} \mathrm{~N}$ HSQC experiment selectively detects the resonances of the protons on isotopically labeled nitrogens. Therefore, if the particular resonances of two amide protons are detected in the experiment, it is evidence of ${ }^{15} \mathrm{~N}$ exchange. Using a range of substrate sequences, other research groups have documented that the protons of the ${ }^{15} \mathrm{~N}$-labeled glutamine amides consistently resonate with the same chemical shifts and peaking patterns, 6.9 and $7.5 \mathrm{ppm}$ as sharp singlets. ${ }^{10}$ However, these chemical shifts are not static and do vary slightly between peptide sequences or if an intact protein such as $\alpha \mathrm{C}$ is being analyzed. A structure of the ${ }^{15} \mathrm{~N}$-labeled glutamine may be seen in Figure 8 .

From examining the spectra in Figure 9, it can

be seen that FXIIIa behaviors were not consistent

among the three different peptide sequences.

Beginning with K9(1-10), the FXIIIa-mediated

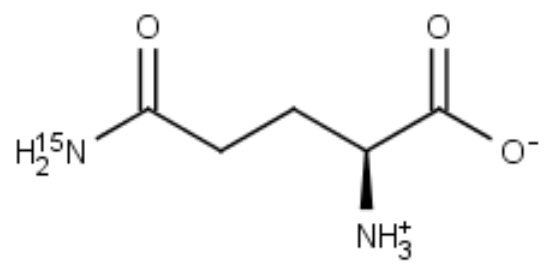

reaction displayed a very clear peaking pattern that

Figure 8: ${ }^{15} \mathrm{~N}$-labeled glutamine at its amide group. 
other research groups have previously proven indicative of the enzymatically mediated isotopic amide exchange. The resonances appeared at the anticipated frequencies and rendered two sharp, separate peaks. ${ }^{10}$ In the absence of FXIIIa, there were no resonating protons in the spectra, indicating that the ${ }^{15} \mathrm{NH}_{4}$ was not exchanged at the reactive glutamine.
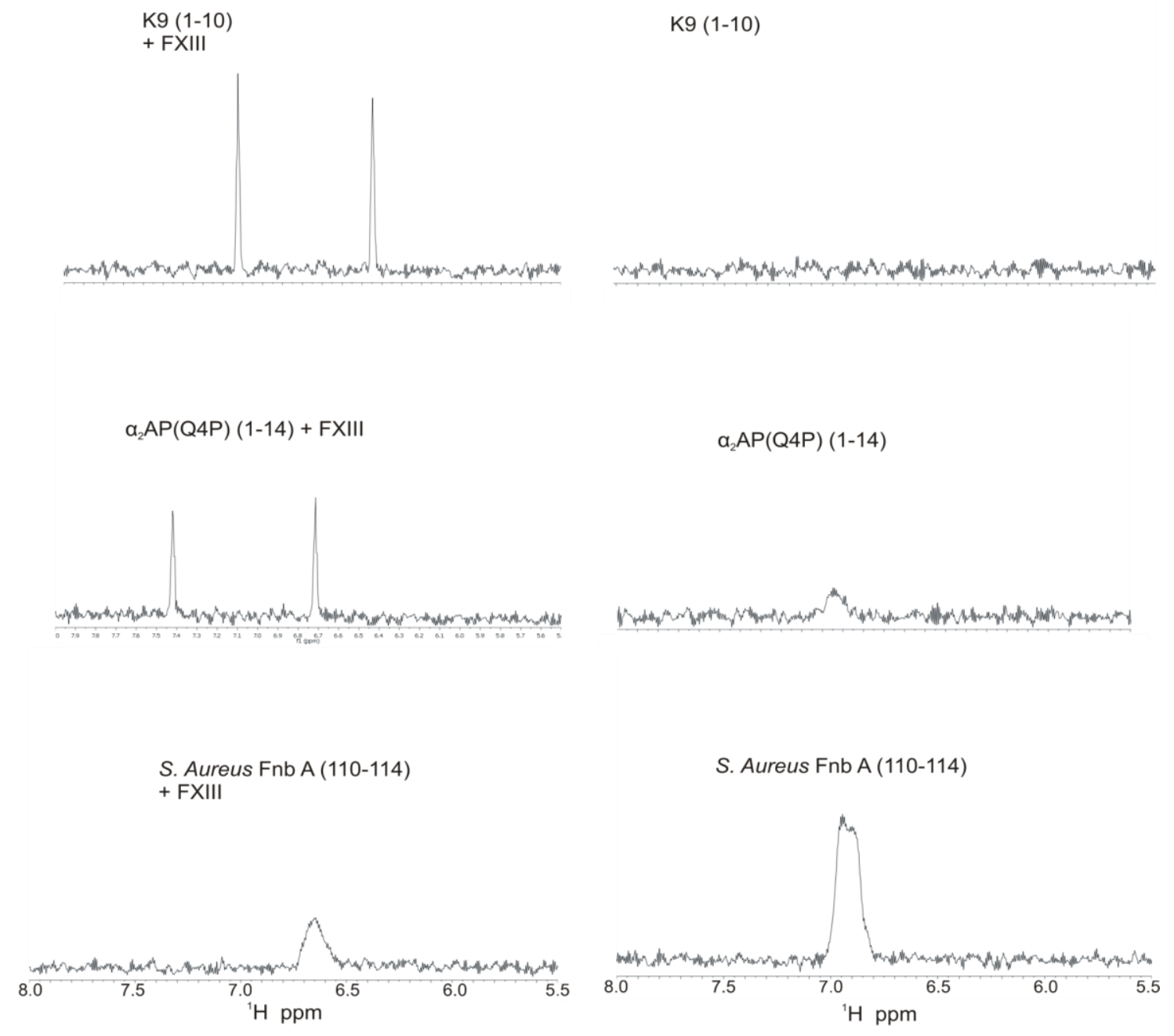

Figure 9: $1 \mathrm{D}{ }^{15} \mathrm{~N}$ HSQC NMR spectra for region of interest $(5.5-8 \mathrm{ppm})$ in FXIIIa-mediated ${ }^{15} \mathrm{~N}$-exchange of substrate models. All samples includes $400 \mu \mathrm{M}$ peptide, $20 \mathrm{mM}$ borate buffer $(\mathrm{pH} 7), 50 \mathrm{mM} \mathrm{CaCl}_{2}, 100 \mathrm{mM}{ }^{15} \mathrm{~N}$ $\mathrm{NH}_{4} \mathrm{Cl}$ and varying by the addition or omission of $400 \mathrm{nM}$ FXIII. Samples were $10 \% \mathrm{D}_{2} \mathrm{O}$. 
The next two substrates rendered more interesting results. The $\alpha_{2} \mathrm{AP}(\mathrm{Q} 4 \mathrm{P})(1-15)$ displayed the correct carboxyamide protons frequencies in the FXIIIa-mediated reaction, which was expected. However, in the absence of FXIIIa, there was a new weak resonance in the region between the observed locations of the two enzymatic peaks. The unexpected peak suggests that there is a potential nonenzymatically mediated exchange between the peptide and the labeled ammonium. It should be noted that this unexpected peak was distinct to the reaction without FXIIIa and was not evident in the enzymatically reacted $\alpha_{2}$ APQ4P sample's spectrum. The $S$. aureus FnbA(100-114) takes the unanticipated side reaction further by displaying the unknown
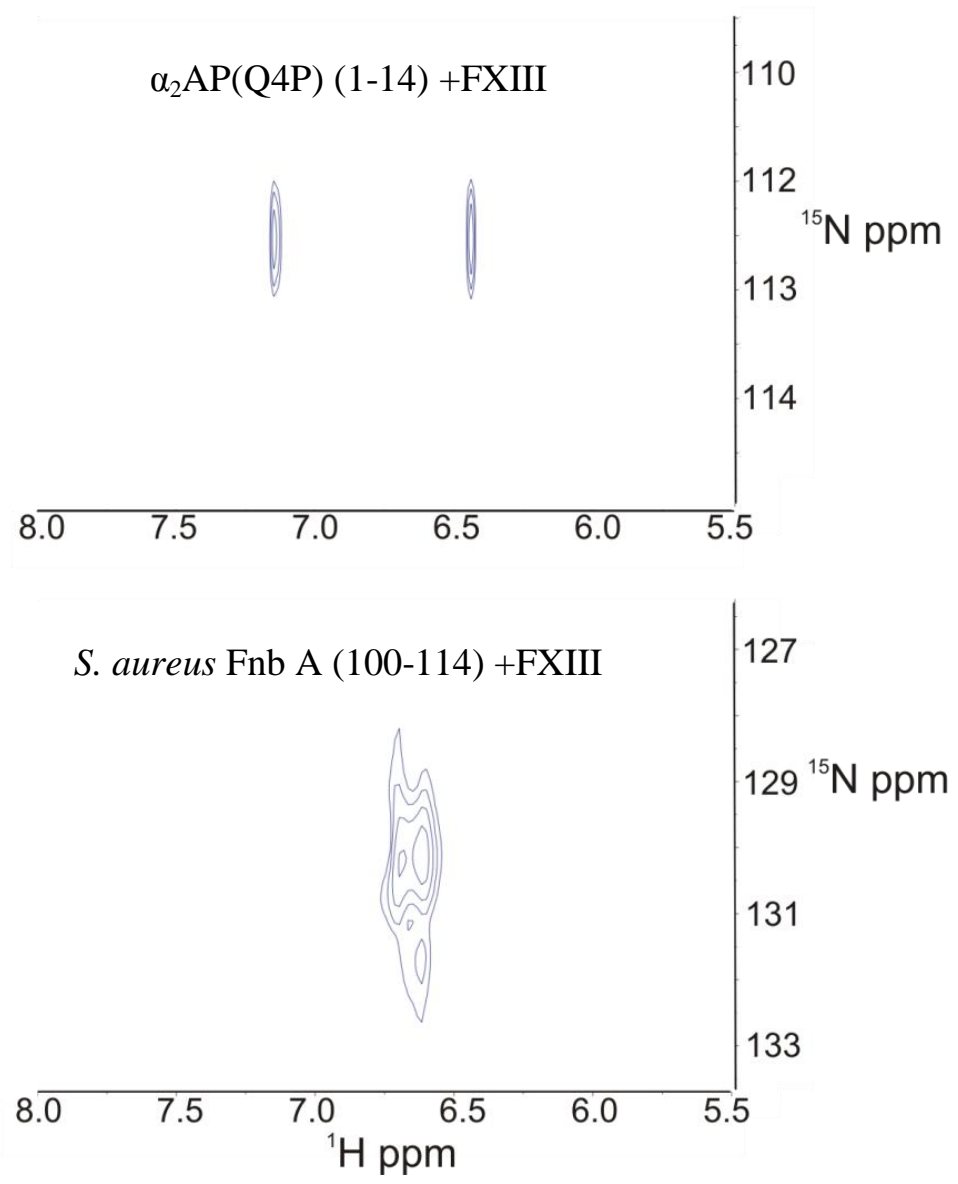

Figure 10: $2 \mathrm{D}{ }^{15} \mathrm{~N}$ HSQC NMR spectra of $\alpha_{2} \mathrm{AP}(\mathrm{Q} 4 \mathrm{P})(1-14)$ and $S$. aureus Fnb A (100-114) in the presence of FXIII. Spectra were collected as previous work of Dr. Prakash Doiphode. resonance at approximately 7

ppm in both the FXIIIa and nonFXIIIa-mediated reaction. The peaking pattern not only provides evidence of some unanticipated interaction, but also shows that this occurrence hinders the ability of FXIIIa to catalyze the reaction. The unanticipated peak at approximately $7 \mathrm{ppm}$ is the only peak seen in the spectrum of the enzymatic reaction. Neither of the sharp amide singlets is observed, indicating that the 
expected ${ }^{15} \mathrm{~N}$-glutamine exchange had not taken place.

Previously generated 2D HSQC NMR spectra of $\alpha_{2} \mathrm{AP}(\mathrm{Q} 4 \mathrm{P})$ (1-14) and $S$. aureus Fnb A (100-114) in the presence of FXIIIa and ${ }^{15} \mathrm{NH}_{4}$ were reviewed ${ }^{10}$. They may be seen in Figure 10. The results showed a positive correlation to the results of the 1D spectra in Figure 9. The $\alpha_{2} \mathrm{AP}(\mathrm{Q} 4 \mathrm{P})$ peptide spectrum shows two strong peaks that resonate at approximately 6.5 and 7.3

ppm in the ${ }^{1} \mathrm{H}$ dimension, which correlates to the chemical shifts observed in 1D resonances. Also, the two peaks fall in a reasonable range in the ${ }^{15} \mathrm{~N}$ dimension to be classified as glutamine side chain amide protons (110-115 ppm). Though not giving the clean amide peaks, the $S$. aureus Fnb A peptide produced a similar peak in both 1D and 2D HSQC spectra. The large, broad peak falls at the same ${ }^{1} \mathrm{H}$ frequency in both $1 \mathrm{D}$ and $2 \mathrm{D}$ spectra. However, the ${ }^{15} \mathrm{~N}$ frequency resonates at approximately $130 \mathrm{ppm}$, outside of the plausible glutamine side chain amide range. The ${ }^{15} \mathrm{~N}$ must have incorporated into the peptide in a manner other than a traditional transglutamination because the appearance of any resonance is indicative of ${ }^{15} \mathrm{~N}$ being bonded to the peptide.

\subsection{TOCSY NMR Analysis of FXIII Deamidation with Substrate Peptide Models}

In the absence of a lysine mimic, FXIIIa can facilitate a deamidation of the reactive glutamine to a glutamic acid. This chemical reaction can be monitored via a 2D TOCSY NMR experiment. In order to have a base of comparison for the deamidation reactions, the chemical shifts of the native Q-containing peptides first had to be identified. The TOCSY spectra of native S. aureus Fnb A (100-114), $\alpha_{2} \mathrm{AP}(\mathrm{Q} 4 \mathrm{P})$ (1-15) and K9 (1-10) were collected and analyzed. The spectra of each peptide and assigned chemical shift table may be seen in Appendix A. Due to complications in sample preparation of the FXIIIa-reacted peptides, the spectral quality was greatly reduced which hindered the ability to fully assign all amino acid chemical shifts. 
Therefore, a visualization of the deamidation was not possible, but the assignment of the native peptide spectra provides valuable information for future work.

\subsection{SDS-PAGE Analysis of $\alpha C(233-425)$ Purification}

The peptide substrates served as models to observe FXIIIa's sequence specificity; however, $\alpha \mathrm{C}(233-425)$ allowed the enzyme's activity to be observed in the presence of an intact substrate protein. After being eluted as fractions off the GST-affinity column, the purity of the expressed $\alpha \mathrm{C}(233-425)$ was assessed by the use of SDS-PAGE. In Figure 11, the gradient polyacrylamide gel stained with Coomassie Blue may be seen. The cellular protein solution prior to being loaded on the GST-column was run in Lane 1. As expected, it contained numerous proteins based on the many bands seen in the gel. The same observation can also be made of Lanes 2 and 3. Lane 2 holds the eluent released while the protein solution was loaded on the column. This eluent also contains many proteins because the only protein that is selectively maintained on the column is the GST-tagged $\alpha \mathrm{C}$. Lane 3 contains the eluent from washing the protein-bound column with PBS in order to remove any residual, extraneous proteins. This wash is why the same band pattern is observed in Lane 3 as with the preceding two lanes, because Lanes 1-3 all contain the same proteins, excluding $\alpha \mathrm{C}$. Lanes 4 and 5 both contain separately eluted fractions of $\alpha \mathrm{C}(233-425)$. Because of the presence of only one band in each, this confirmed the fractions' purities. Also, the bands in Lanes 4 and 5 ran level with the molecular marker indicating $20 \mathrm{kDa}$, which is in expected mass range of the protein $(\mathrm{MW}=19,500 \mathrm{Da})$. 


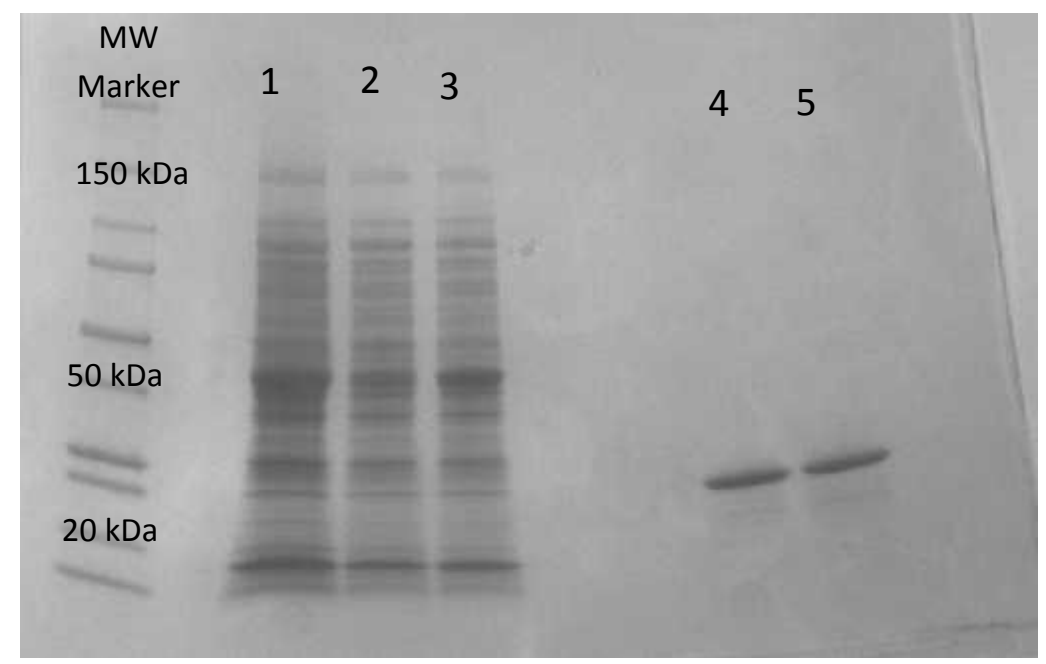

Figure 11: Gradient (4-20\%) polyacrylamide gel stained with Coomassie Blue. Lane 1: Cell solution before loaded on the column; Lane 2: the load eluent; Lane 3: wash eluent; Lanes 4 and 5: collected $\alpha \mathrm{C}(233-425)$ fractions. $\alpha \mathrm{C}(233-425) \mathrm{MW}=19,500 \mathrm{Da}$.

\subsection{SDS-PAGE Analysis of $\alpha C(233-425)$ Crosslinking with DC}

The reactivity of $\alpha \mathrm{C}(233-425)$ as a FXIIIa substrate was confirmed by the protein's ability to be crosslinked to the lysine-mimic, dansylcadaverine (DC). The structure of DC may be seen in Figure 12. Activated via IIa and $\mathrm{Ca}^{2+}$, FXIIIa catalytically initiated the transglutamination of the protein's reactive glutamines with DC. When exposed to UV light, the DC fluoresces which will allow the crosslinked $\alpha \mathrm{C}+\mathrm{DC}$ bands to be visualized. The gel of crosslinked $\alpha \mathrm{C}$-DC exposed to UV light may be seen in Figure 13. The band at $20 \mathrm{kDa}$ can be seen to fluoresce, indicating that the suspected protein band observed in the eluted fractions was $\alpha \mathrm{C}$.

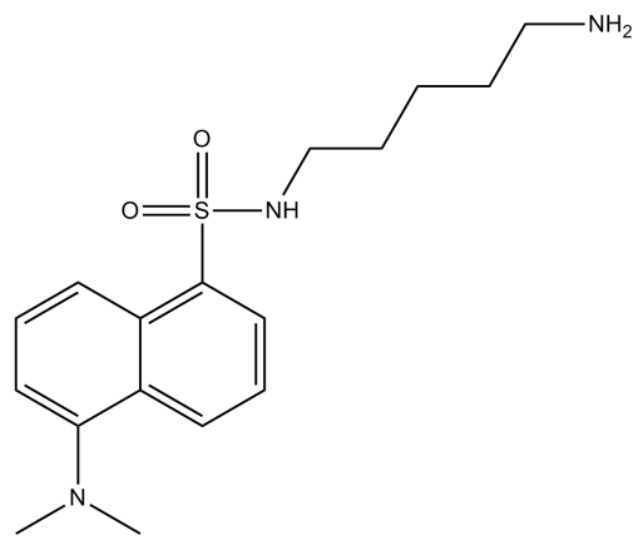

Figure 12: Structure of the lysine-mimic, dansylcadaverine. (DC) 


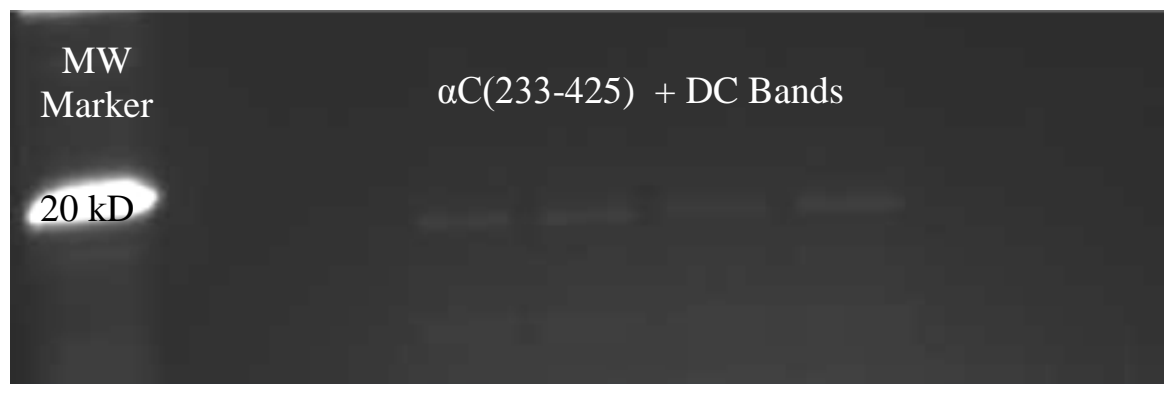

Figure 13: SDS-PAGE 4-20\% gradient gel displaying crosslinked $\alpha \mathrm{C}(223-425)(7.9 \mu \mathrm{M})$ with dansylcadaverine exposed to UV light. The four $\alpha \mathrm{C}+\mathrm{DC}$ bands are faint compared to the marker, but are discernible.

\subsection{MALDI-TOF MS Analysis of $\alpha C(233-425) Q^{328}$-GEE Crosslinking}

To monitor the rate at which FXIIIa reacts with the targeted $\mathrm{Q}^{328}$ of $\alpha \mathrm{C}(233-425)$, the protein was crosslinked with the lysine-mimic, glycine ethyl ester. The structure of GEE may be seen in Figure 14. Samples were allowed to react for discrete periods of time prior to a FXIIIa quench. Glutamine 328 was selectively monitored via a chymotrypsin digest followed by MALDI-TOF MS analysis. The digested fragment, $\alpha \mathrm{C}(315-342)$, containing the reactive $\mathrm{Q}$ of interest, exhibited a mass of $2448 \mathrm{~m} / \mathrm{z}$. As the reaction time was increased, the appearance of a new fragment for GEE (86 m/z) crosslinked with the Q-containing $\alpha \mathrm{C}(315-342)$ was observed. From Figure 15, the MALDI-TOF MS spectra of the chymotrypsin digests at different FXIIIa quench times may be seen, with the field zoomed to feature the Q-containing peak and the $\mathrm{GEE}+\mathrm{Q}^{328}$ peak. As the reaction time increased, the intensity of the crosslinked peak grew in relative intensity while the Q-reactant's peak diminished. There were some extraneous weak peaks that appeared between the two peaks of interest.

These are contaminants and not sodiated or potassiated peaks that need to be accounted.

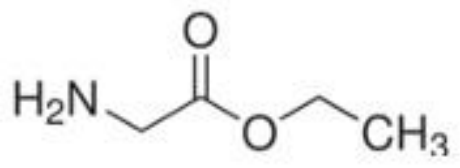

To analyze the kinetic results in a more quantitative manner, the changing concentration of the

Figure 14: Structure of the lysine-mimic glycine ethyl ester (GEE). 
free $\mathrm{Q}^{328}$ peak was monitored. The consumption of the Q-reactant was monitored in each spectrum by the following mathematical operation:

$$
\frac{\text { reactant peak height }}{\text { reactant peak height }+ \text { product peak height }} * \text { concentration of peptide. }{ }^{12}
$$

The results of the MALDI-TOF MS assay with respect to consumption of reactant can be seen in Figure 16. From the regression of the data, it can be seen that FXIIIa's transglutamination of $\mathrm{Q}^{328}$ progressed in a linear fashion. However, it is very clear that $\mathrm{Q}^{328}$ was not completely crosslinked with GEE because the free Q peak never goes away in Figure 15 and the concentration of reactant only decreases by approximately 30 percent in Figure 16.

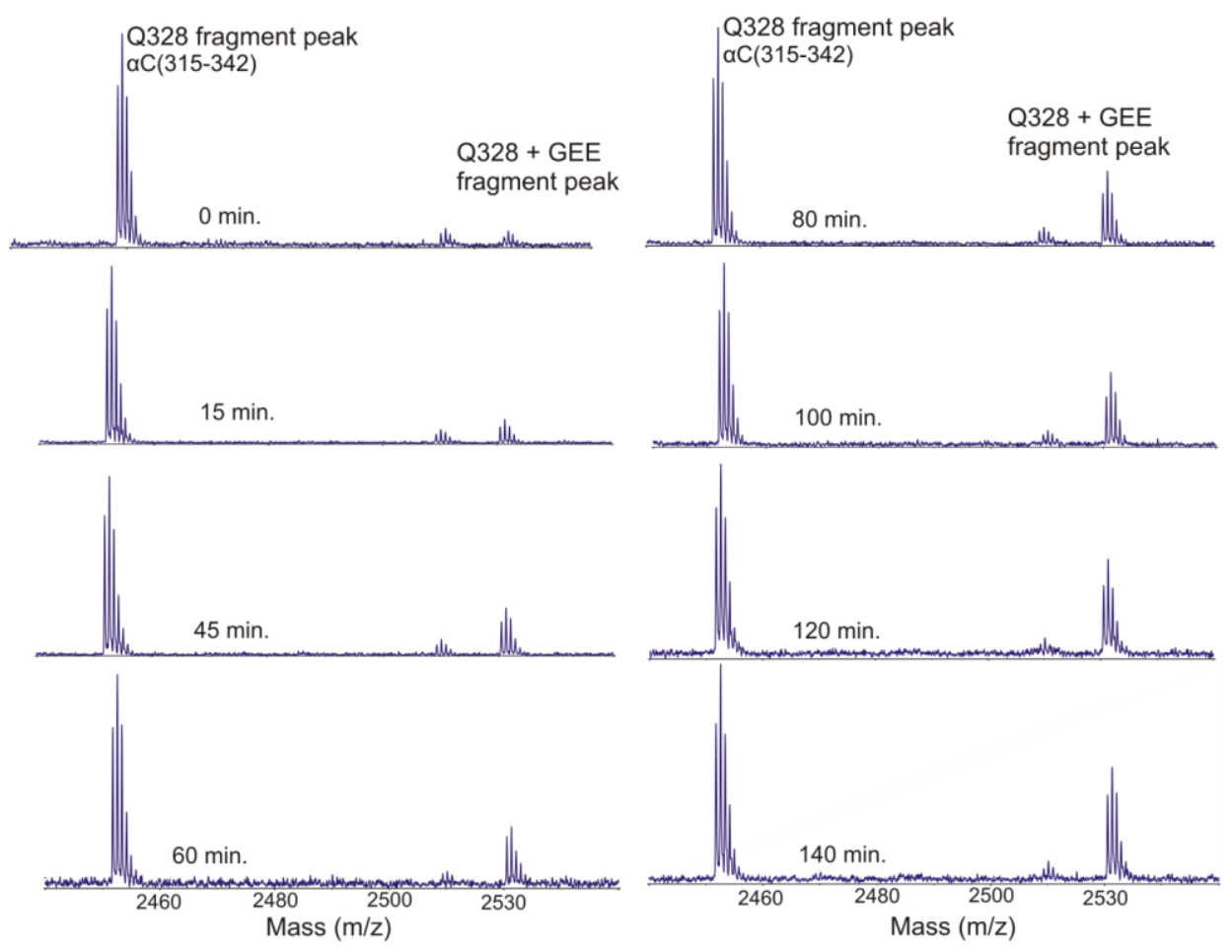

Figure 15: The MALDI-TOF MS spectra of the chymotrypsin digested $\alpha \mathrm{C}(233-425)$ with varying times of FXIIIIa transglutamination with glycine ethyl ester. Field of vision zoomed to feature the $\mathrm{Q}^{328}$ containg fragment and $\mathrm{Q}^{328}$-fragment+GEE peaks. $\alpha \mathrm{C}(315-342)$ sequence:

${ }^{315}$ NSGSSGTGSTGNQNPGSPRGSTGTW ${ }^{342}$. Concentration of $\alpha \mathrm{C}$ in the assay was $17 \mu \mathrm{M}$. 


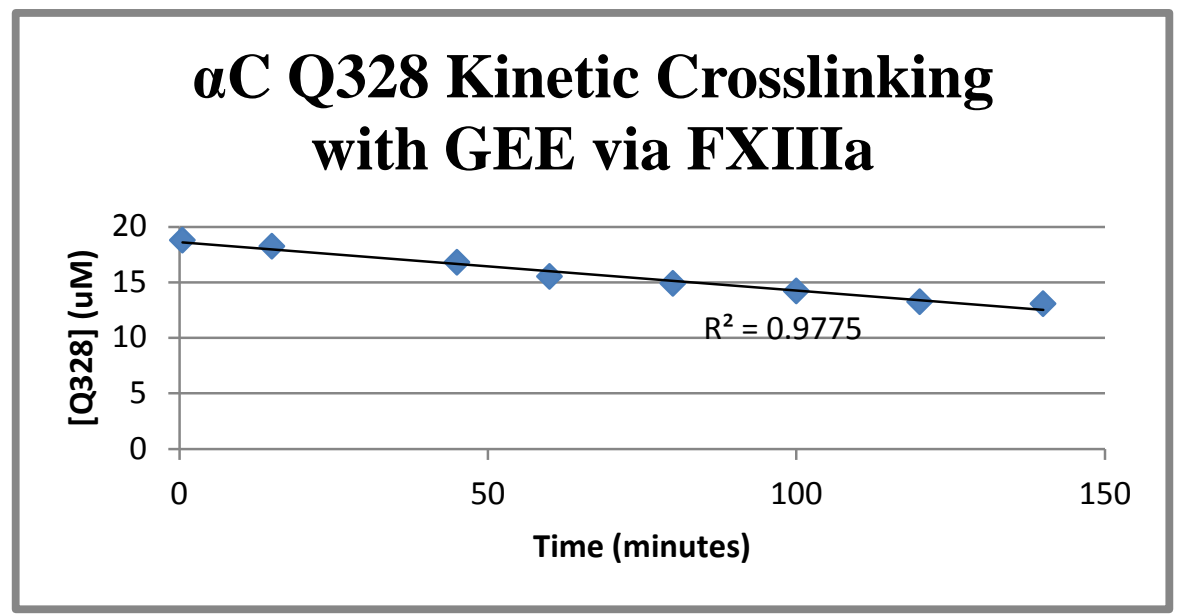

Figure 16: Graph displaying the consumption of the $\alpha \mathrm{C}^{328}$-containing reactant fragment over time. The data is based on the MALDI-TOF MS data seen in Figure 13.

\section{7 ${ }^{15}$ N HSQC NMR Analysis of FXIII ${ }^{15} \mathrm{~N}$-exchange with $\alpha \mathrm{C}(233-425)$}

Due to complications in concentrating the eluted $\alpha \mathrm{C}(233-425)$ fractions, no stock protein solutions could be generated with a concentration greater than approximately $30 \mu \mathrm{M}$. This low concentration of stock solutions made it more complicated to prepare NMR samples that contained enough $\alpha \mathrm{C}(233-425)$ to be visualized in the experiment. However, one successful 2D ${ }^{15} \mathrm{~N}$ HSQC NMR experiment was conducted on the protein in the presence of nonproteolytically activated FXIIIa and ${ }^{15} \mathrm{NH}_{4}$. The final protein concentration in the reaction sample was $20 \mu \mathrm{M}$, which proved to be the minimal concentration of protein that could be visualized in an ${ }^{15} \mathrm{~N}$ HSQC experiment. As in the isotopic transglutamination reactions that were conducted with the peptide substrate models, FXIIIa can incorporate the labeled nitrogen at the glutamine side chain amide so it may be visualized using ${ }^{15} \mathrm{~N}$ HSQC. The resulting $2 \mathrm{D}$ spectrum may be seen in Figure 17. The $\alpha \mathrm{C}(233-425)$ protein contains three glutamines, $\mathrm{Q}^{327}, \mathrm{Q}^{328}$ and $\mathrm{Q}^{366}$, with the latter two being the residues of enzymatic focus. ${ }^{9}$ In the spectrum, two sets of glutamine chain amide proton peaks are observed. A distinct pair of ${ }^{15} \mathrm{~N}$-attached proton peaks may be seen at $(112.7,7.55 \mathrm{ppm})$ and $(112.7,6.85 \mathrm{ppm})$ in the ${ }^{15} \mathrm{~N}$ and ${ }^{1} \mathrm{H}$ dimensions, accounting for the isotopic exchange at one glutamine. Another pair of peaks was observed at approximately 112.5 
ppm in the ${ }^{15} \mathrm{~N}$ dimension; however, this peaking pattern was not as well resolved in the ${ }^{1} \mathrm{H}$ dimension. One of the peaks in the pair was clear at ${ }^{1} \mathrm{H}$ chemical shift of $6.8 \mathrm{ppm}$, while the other peak was split into two separate ${ }^{1} \mathrm{H}$ chemical shifts, 7.45 and $7.48 \mathrm{ppm}$. The newer peaking pattern seen in the pair of peaks at $112.8 \mathrm{ppm}$ in the ${ }^{15} \mathrm{~N}$ dimension may be related to the chemical environment surrounding the second reactive $\mathrm{Q}$ or the contribution of a third glutamine residue.

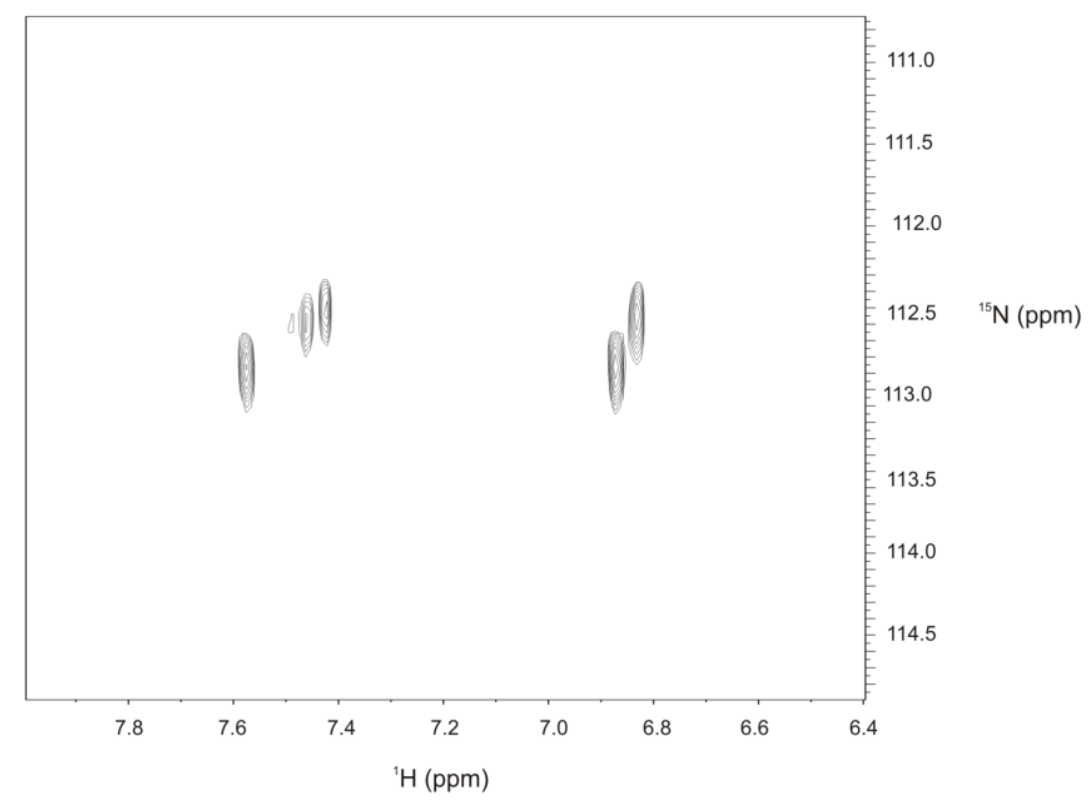

Figure 17: $2 \mathrm{D}{ }^{15} \mathrm{~N}$ HSQC NMR spectra of $\alpha \mathrm{C}(233-425) 20 \mu \mathrm{M}$ in the presence of ${ }^{15} \mathrm{NH}_{4} \mathrm{Cl}$ and nonproteolytically activated FXIII. 


\section{Discussion}

Blood coagulation is a dynamic process that involves a cascade of enzymatic activations and reactions. The final stages of the clotting cascade revolve around the interactions among thrombin (IIa), Factor XIII (FXIIII), calcium and fibrinogen which facilitate the ultimate formation of a hard clot. IIa, a serine protease, cleaves fibrinogen into fibrin monomers and removes the activation peptide from the FXIII. The increased $\mathrm{Ca}^{2+}$ concentration allows the active FXIII- $\mathrm{A}_{2}$ subunit to dissociate from the inhibitory FXIII- $\mathrm{B}_{2}$ subunit and maintains the enzyme's activity during coagulation. ${ }^{2}$ Activated FXIII (FXIIIa) then facilitates the covalent crosslinking between fibrin monomers, forming a hard blood clot. FXIIIa achieves this crosslinking by its enzymatic ability to crosslink fibrin glutamines with normally fibrin lysine residues. The $\alpha \mathrm{C}$ domains of fibrin monomers are one of the key target sites for covalent crosslinking by FXIIIa. However, FXIIIa does not uniformly react with glutamines found in vivo. Only selected Q-containing sequences are actually targeted by FXIIIa transglutamination. ${ }^{3}$ The exact consensus sequence of FXIIIa's enzymatic activity remains unknown, but with the use of peptide substrate models and the $\alpha \mathrm{C}(233-425)$ protein, a greater insight into the enzyme's selectivity may be deduced.

\subsection{FXIIIa Interactions with Peptide Substrate Models}

To monitor FXIIIa's specificity towards a range of Q-containing amino acid sequences, S. aureus Fnb A (100-114), $\alpha_{2} \mathrm{AP}(\mathrm{Q} 4 \mathrm{P})$ (1-15) and K9 (1-10) peptide interactions with the enzyme were studied. FXIIIa's ability to exchange glutamine chain amides with ${ }^{15} \mathrm{NH}_{4} \mathrm{Cl}$, a lysine mimic, provides a valuable isotopic labeling technique. ${ }^{10}$ The presence or absence of an

${ }^{15} \mathrm{~N}$-labeled glutamine after a FXIIIa-mediated reaction was used to evaluate the extent of enzymatic transglutamination. Using ${ }^{15} \mathrm{~N}$ HSQC NMR and MALDI-TOF MS experiments, the enzymatic reaction could be monitored for each peptide substrate model. 
By MALDI-TOF MS analysis, the exchange of the peptides' Q- $\mathrm{NH}_{2}$ for ${ }^{15} \mathrm{NH}_{2}$ would appear as a shift of $1 \mathrm{~m} / \mathrm{z}$. From observing the results for each peptide, it was evident that not all three peptides were successfully ${ }^{15} \mathrm{~N}$-labeled by FXIIIa. In Figure 7, $\alpha_{2} \mathrm{AP}(\mathrm{Q} 4 \mathrm{P})(1-15)$ and K9 (1-10) can be seen to display an upwards shift in $1 \mathrm{~m} / \mathrm{z}$ unit in the FXIIIa-reacted spectra compared to unlabeled controls. This indicates a successful transglutamination because of the 1 $\mathrm{m} / \mathrm{z}$ difference between the two isotopes of nitrogen $\left({ }^{14} \mathrm{~N}\right.$ and $\left.{ }^{15} \mathrm{~N}\right)$. However, this shift in the MALDI-TOF MS spectrum of $S$. aureus Fnb A(100-114) in the presence of FXIIIa and ${ }^{15} \mathrm{NH}_{4}$ was not observed. This lack of change in $\mathrm{m} / \mathrm{z}$ is why the spectrum of the unlabeled control is identical to the spectrum of the enzymatically reacted S. aureus peptide. Therefore, the MALDITOF MS data suggest that only $\alpha_{2} \mathrm{AP}(\mathrm{Q} 4 \mathrm{P})(1-15)$ and $\mathrm{K} 9$ (1-10) are capable of undergoing enzymatic isotopic exchange via FXIIIa, while S. aureus Fnb A(100-114) is not.

In the ${ }^{15} \mathrm{~N}$ HSQC NMR studies, the change in $\mathrm{m} / \mathrm{z}$ of isotopic labeling was not the aim. Rather, the incorporation of an atom with spin $=1 / 2,{ }^{15} \mathrm{~N}$, was the characteristic that was taken advantage of in these experiments. In the ${ }^{15} \mathrm{~N}$ HSQC NMR experiment, only the proton attached to nitrogen-15 can resonate. This indicates that an unlabeled protein should show no resonances in its HSQC spectrum, while an ${ }^{15} \mathrm{~N}$-labeled glutamine would produce two peaks for each ${ }^{15} \mathrm{~N}$ attached proton. ${ }^{10}$

The $1 \mathrm{D}{ }^{15} \mathrm{~N}$ HSQC spectra displayed in Figure 9, revealed that a range of peaking patterns could be observed with the peptide substrate models. K9(1-10) presented the expected outcome of the experiment. The unlabeled control showed no peaks, while the FXIIIa-reacted sample showed the two sharp ${ }^{15} \mathrm{~N}$-amide proton peaks as anticipated. Similarly, $\alpha_{2} \mathrm{AP}(\mathrm{Q} 4 \mathrm{P})(1-$ 15) showed the sharp twin peaks in the spectrum of the FXIII-reacted sample, but the unlabeled control spectrum was not clear like that of K9 (1-10). In the nonenzymatically reacted sample, 
there appeared a weak, broad peak at approximately 7 ppm, which was an unexpected result. This unexpected resonance in the nonenzymatically reacted $\alpha_{2} \mathrm{AP}(\mathrm{Q} 4 \mathrm{P})(1-15)$ spectrum was ruled out as an artifact when a similar unknown peak appeared in both of the spectra of S. aureus Fnb A (110-114). In the absence of FXIIIa, the ${ }^{15} \mathrm{NH}_{4}$ and $S$. aureus Fnb A peptide produced a strong, broad resonance at approximately the same chemical shift of $7 \mathrm{ppm}$. The same unknown peak was also seen in the spectrum of $S$. aureus Fnb A with the addition of FXIIIa. The resonance in this spectrum is weaker than that of the one seen in the spectrum of the peptide control, yet the peak is still very discernible in the spectrum.

By complementing the MALDI-TOF MS data with the results of the ${ }^{15} \mathrm{~N}$ HSQC NMR results, a more encompassing picture can be formed about the substrate specificity of FXIIIa. From the MALDI-TOF MS data, an answer to whether or not there was FXIIIa-facilitated isotopic exchange at the reactive glutamine's amide group could be deduced. The ${ }^{15} \mathrm{~N}$ HSQC NMR experiments also provided this data; however, NMR also allowed for the examination of any dynamic ${ }^{15} \mathrm{NH}_{4}$-peptide interactions that do not result in a $1 \mathrm{~m} / \mathrm{z}$ shift. This allowed FXIIIa transglutaminase activity to be monitored and any enzymatically hindering processes to be observed as well.

By reviewing the data in Figures 7 and 9, it can be seen that both methods agreed that the three examined peptide models showed varying specificity towards FXIIIa. K9 (1-10) peptide was a very effective substrate model in targeting FXIIIa's enzymatic activity. Both NMR and MS data show a lack of any ${ }^{15} \mathrm{NH}_{4}$ interactions with $\mathrm{K} 9$ without the presence of FXIIIa, and both confirm the isotopic exchange when the enzyme is present. This was the ideal situation expected for any peptide that functions strongly as a FXIIIa substrate. $\alpha_{2} \mathrm{AP}(\mathrm{Q} 4 \mathrm{P})(1-15)$ also was a 
successful target of FXIIIa's activity. The appearance of two sharp NMR peaks and the $1 \mathrm{~m} / \mathrm{z}$ MS shift confirms $\alpha_{2} \mathrm{AP}(\mathrm{Q} 4 \mathrm{P})$ 's ability to function as a FXIIIa substrate.

The peptide that proved to be the least effective FXIIIa substrate was S. aureus Fnb A (100-114). There was no shift observed in the centroid of the MALDI-TOF MS spectrum nor was there an appearance of the anticipated amide proton peaks in the HSQC spectrum. Additionally, the NMR spectra of S. aureus Fnb A (100-114) displayed the peptide's ability to actively participate in an unknown isotopic interaction in both the presence and absence of FXIIIa by the appearance of a broad peak at between 6.5 and $7 \mathrm{ppm}$. This resonance was unexpected because any ${ }^{15} \mathrm{~N}$ HSQC NMR resonance, even a weak one, indicates that a labeled nitrogen was incorporated into the peptide structure in some manner. However, this isotopic addition must be distinct from a transglutamination for two reasons: there was no appearance of the two sharp glutamine amide proton peaks in the HSQC spectrum nor was there a $1 \mathrm{~m} / \mathrm{z}$ shift in the MALDI-TOF MS spectrum. As seen in Figure 9, the S. aureus peptide participated in the same nonenzymatic interaction that $\alpha_{2} \mathrm{AP}(\mathrm{Q} 4 \mathrm{P})(1-15)$ had the propensity to do. However, $S$. aureus Fnb A (100-114) showed a much higher affinity to participate in this unanticipated ${ }^{15} \mathrm{~N}$ exchange in the absence of the enzyme than the $\alpha_{2} \mathrm{AP}(\mathrm{Q} 4 \mathrm{P})$ peptide. The interaction with the ${ }^{15} \mathrm{NH}_{4} \mathrm{Cl}$ appeared to be so favorable that it out-competed FXIIIa attempts to carry out a transglutamination reaction. This suggestion is based on the appearance of the same, yet more diminished peak in the FXIIIa-containing S. aureus Fnb A (100-114) spectrum relative to the nonenzymatic sample. Therefore, it can be seen that the unanticipated isotopic interaction renders the peptide unable to undergo a FXIIIa-mediated reaction.

In order to provide further insight into the unexpected 1D HSQC peak seen between 6.5 and $7.0 \mathrm{ppm}, 2 \mathrm{D}{ }^{15} \mathrm{~N}$ HSQC NMR was utilized. Previously produced 2D HSQC spectra for the 
FXIIIa- ${ }^{15} \mathrm{NH}_{4}$ reactions for both the $S$. aureus Fnb A and $\alpha_{2} \mathrm{AP}(\mathrm{Q} 4 \mathrm{P})$ peptides were used to view the ${ }^{15} \mathrm{~N}$ chemical shift of the peak. ${ }^{11}$ The 1D HSQC spectra chemical shifts are measured in the ${ }^{1} \mathrm{H}(\mathrm{ppm})$ dimension, while a 2D spectrum will allow resonances to be measured in both the ${ }^{1} \mathrm{H}$ and ${ }^{15} \mathrm{~N}(\mathrm{ppm})$ dimensions.

As seen in Figure 10, $\alpha_{2} \mathrm{AP}(\mathrm{Q} 4 \mathrm{P})$ (1-15) displays two peaks that resonate with ${ }^{1} \mathrm{H}$ chemical shifts in the region of 7.5-6.5 ppm, the same frequencies as the sharp peaks seen in the 1D spectrum of the peptide in Figure 9. The chemical shift of the peaks in the ${ }^{15} \mathrm{~N}$ dimension is also in the normal glutamine amide region, $110-115 \mathrm{ppm}$. The spectrum of the $\alpha_{2} \mathrm{AP}(\mathrm{Q} 4 \mathrm{P})$ peptide thus serves as a model $2 \mathrm{D}{ }^{15} \mathrm{~N}$ HSQC spectrum of a successful FXIIIa ${ }^{15} \mathrm{~N}$-labeled glutamine. However, the spectrum of the S. aureus peptide displayed the same broad peak as in the 1D spectrum, with the same ${ }^{1} \mathrm{H}$ chemical shift, approximately between 7 and $6.5 \mathrm{ppm}$. The peak in the ${ }^{15} \mathrm{~N}$ dimension had a chemical shift of approximately $131.5 \mathrm{ppm}$. This peak therefore falls well out of the plausible range of glutamine side chain nitrogen protons, again verifying that the isotopic interaction is distinct from the transglutamination facilitated by FXIIIa.

An explanation of this unanticipated peak must accommodate the experimental data that has been found. The labeled nitrogen is incorporated into the S. aureus Fnb A (100-114) structure by NMR analysis but there is no change in mass to charge ratio in the MS spectra. This information would appear indicative of the ${ }^{15} \mathrm{~N}$ reacting with the peptide in a novel manner that causes a proton to be lost while the isotope is bonded to the peptide. A reaction with these results would explain why there was a signal in the ${ }^{15} \mathrm{~N}$ HSQC in the absence of FXIIIa and why there was no observed shift the centroid of the MALDI-TOF spectrum. A potentially viable reaction that would explain this data would be one involving the interactions among side chains of the reactive glutamine $\left({ }^{100} \mathrm{SGDQRQVDLIPKKAT}{ }^{114}\right)$, an arginine residue, and ${ }^{15} \mathrm{NH}_{4} \mathrm{Cl}$. The 
proposed mechanism for the reaction may be seen in Figure 18. The N-terminal serine residue's alcohol group could attack the $\delta$-carbon of the glutamine side chain causing a tetrahedral intermediate with an oxyanion (Step A). This unstable intermediate would allow the unlabeled, H-bonded $\mathrm{NH}_{2}$ to leave as the carbonyl of glutamine reforms (Step B). The new serineglutamine intermediate then allows ${ }^{15} \mathrm{NH}_{2}$ to be incorporated at the glutamine side chain (Step C).
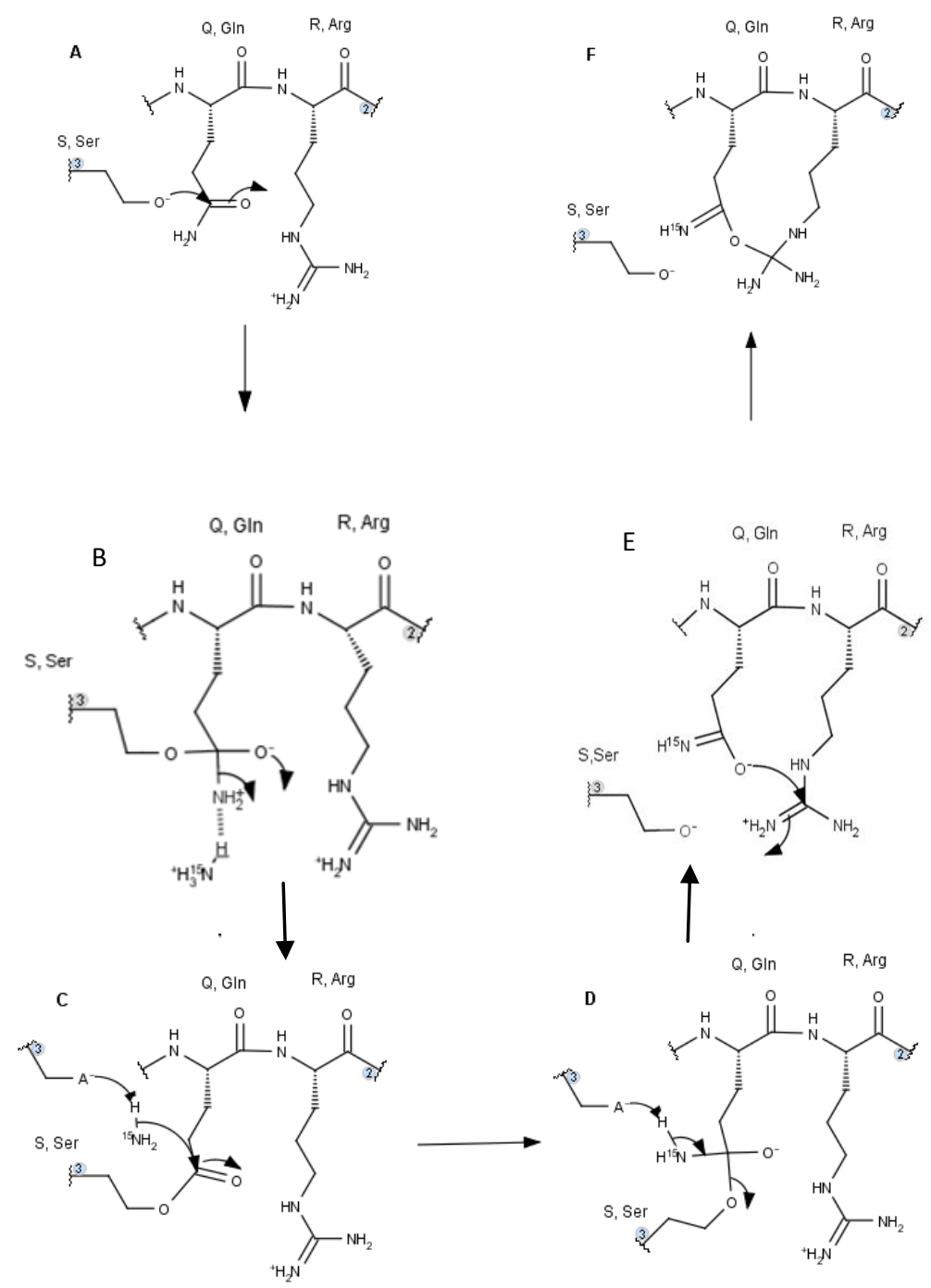

Figure 18: Proposed mechanism for isotopic reaction observed in ${ }^{15} \mathrm{~N}$ HSQC experiments. The attacking serine can be function intramolecularly or as a separate peptide residue. The general acid groups used in Steps $\mathrm{C}$ and $\mathrm{D}$ could be serine or aspartate groups on the peptide or neighboring peptides.

This portion of the reaction manages the introduction of the ${ }^{15} \mathrm{~N}$, while the next step involving 
arginine would account for the loss of the proton. Once the ${ }^{15} \mathrm{~N}$ is incorporated at the $\delta$-carbon of glutamine, instead of reforming the amide, an amidate group could form (Step D). This structure places a double bond between ${ }^{15} \mathrm{~N}$ and $\mathrm{C}$, causing a loss of one attached proton on the labeled nitrogen. This step would explain the lack of a shift in $m / z$ in the MS spectra following the reaction. The oxyanion of the amidate form of glutamine could then be stabilized by attacking the guanidinium carbon of the adjacent arginine (Step E). This final step would stabilize the negatively charged oxygen and relieve the natural charge on the arginine group. The proposed structure of the product can be seen in Step F of Figure 18.

This proposed structure would satisfy both the data that was presented in the ${ }^{15} \mathrm{~N}$ HSQC NMR and MALDI-TOF MS results. Firstly, the labeled nitrogen in the structure could cause a visible resonance with ${ }^{15} \mathrm{~N}$ HSQC analysis. The peaks ${ }^{15} \mathrm{~N}$ frequency being different from that of normal glutamine amides can be explained by the change in nitrogen hybridization. In the native glutamine, the nitrogen is $\mathrm{sp}^{3}$ hybridized, while in the proposed structure the ${ }^{15} \mathrm{~N}$ is $\mathrm{sp}^{2}$ hybridized. This could cause the nitrogen proton peak to resonate at a higher frequency in the nitrogen dimension compared to glutamine chain amides, which was observed in Figure 10. Secondly, the linking of the glutamine and arginine residues at the glutamine chain oxygen to the guandinium carbon of arginine allows for the loss of a proton. This was a critical factor in proposing the structure, because it must accommodate the lack of $\mathrm{m} / \mathrm{z}$ shift seen in the MS data. Additionally, the binding of the reactive Q to arginine could explain why FXIIIa was unable to facilitate the anticipated transglutamination. $\alpha_{2} \mathrm{AP}(\mathrm{Q} 4 \mathrm{P})$ may also be able to mildly undergo this non enzymatic reaction in a similar fashion because of the appearance of a small broad peak at approximately $7.0 \mathrm{ppm}$ in the absence of FXIIIa. However, because of the absence of an arginine residue, the mechanism would have to be distinct from the one proposed in Figure 18. 
A future method to verify this mechanism or provide further insight into the ${ }^{15} \mathrm{NH}_{4} \mathrm{Cl}$-mediated reaction would be to conduct a tandem MS/MS mass spectrometry experiment. This strategy would allow for observation of exactly which portion of the peptide has ${ }^{15} \mathrm{~N}$ incorporated and consequently which residue(s) is causing the unanticipated side reaction.

Another FXIIIa quality that was to be taken advantage of in analyzing substrate specificity was the enzyme's ability to facilitate a deamidation of a glutamine to a glutamic acid in the absence of a lysine mimic. This shift from a $Q$ to $E$ residue in the peptide structures could be monitored by total correlation spectroscopy (TOCSY) NMR experiments. This NMR experiment allows each proton of the amino acid chains to be assigned and monitored. The deamidation reaction of FXIIIa would produce a spectrum distinct from a nonenzymatically reacted peptide sample, based on the appearance of Q or E resonance patterns. ${ }^{3}$ As in ${ }^{15} \mathrm{~N}$ HSQC NMR experiment, nonenzymatically reacted peptide samples were generated first as a basis of comparison. The TOCSY spectra of the assigned amino acid residues of S. aureus Fnb A (100114) and $\alpha_{2} \mathrm{AP}(\mathrm{Q} 4 \mathrm{P})(1-15)$ may be seen in Appendix A. In order to better visualize the proton peaks, the $\mathrm{pH}$ of the samples were lowered to approximately $\mathrm{pH} 3.5$. Unfortunately, various concentration and $\mathrm{pH}$ complications arose during preparation of the FXIIIa-reacted peptide samples. This resulted in spectra that displayed weak and unclear resonances. For this assay, certain parameters need to be further optimized to aid in producing more resolved and useful spectra. However, the native Q-containing TOCSY spectra of the S. aureus Fnb A and $\alpha_{2} \mathrm{AP}(\mathrm{Q} 4 \mathrm{P})$ peptides are reported in Appendix A because this was the first time these peptide proton frequencies were assigned and the information can serve as a future tool in analyzing the deamidation ability of FXIIIa. 


\subsection{FXIIIa Interactions with $\alpha \mathrm{C}(233-425)$}

To further evaluate the catalytic capabilities of FXIIIa, an intact substrate protein was analyzed. The $\alpha \mathrm{C}$ domain of fibrin monomers is the target of FXIIIa transglutamination that causes the covalent crosslinking of the fibrin clot. The $\alpha \mathrm{C}(233-425)$ region contains three glutamines with two, $\mathrm{Q}^{328}$ and $\mathrm{Q}^{366}$, being potential targets to FXIIIa's enzymatic activity. ${ }^{9}$ The preference of FXIII to these two glutamine residues has yet to be clearly analyzed. Insights into these interactions would provide a clearer view of FXIIIa's substrate specificity.

The intact $\alpha \mathrm{C}(233-425)$ protein was expressed and purified in multiple preparations in order to provide stocks for FXIIIa enzymatic analysis. In order to verify the purity and ability of the protein to be crosslinked by FXIIIa, SDS-PAGE was used. The clear, single bands seen in the collected $\alpha \mathrm{C}(233-425)$ fractions of Figure 11 show that the GST-affinity column successfully isolated the protein. Additionally, when in the presence of the fluorescent lysine-mimic dansylcadaverine, the $\alpha \mathrm{C}(233-425)$ protein displayed FXIIIa transglutamination affinity, as seen in Figure 13. The isolated $\alpha \mathrm{C}$ protein bands of the SDS-PAGE gel were visualized under UV light, indicating that the compound was incorporated into the protein by FXIIIa. This information provided evidence that the expressed protein was in fact $\alpha \mathrm{C}(233-425)$, based on molecular weight and substrate sequence specificity towards FXIIIa.

The MALDI-TOF MS assay designed to observe FXIIIa's ability to crosslink the lysinemimic glycine ethyl ester to $\mathrm{Q}^{328}$ of $\alpha \mathrm{C}(233-425)$ provided information on the catalytic reaction. Using a chymotrypsin digest, the $\mathrm{Q}^{328}$-containing fragment was isolated. From Figure 15, it can seen that in the MALDI-TOF MS spectra of the FXIIIa-facilitated reaction, a GEE+Q ${ }^{328}$ fragment peak appeared over time. When this information was quantified with respect to the loss of the $\mathrm{Q}^{328}$ fragment over time, a linear dependency was observed. However, from Figure 16, it can be seen that the slope of the graph, i.e. reaction velocity, was not as large as would be 
expected with an enzymatic reaction. This observation could be a result of the low concentration of protein that was used in the assay. Because of issues with concentrating $\alpha \mathrm{C}(233-425)$, the assay had to be conducted using lower than desired concentrations of protein. This low substrate concentration could have not met FXIIIa's $\mathrm{K}_{\mathrm{m}}$ value, which would have slowed the progression of the enzyme's functions. Also, continuing work in this study would include conducting the assay again at various $\alpha \mathrm{C}(233-425)$ concentrations in order to collect each distinct slope or reaction velocity. With the reaction velocities over a range of substrate concentrations, a Lineweaver-Burk plot could be generated to render more enzyme kinetic data.

Further studies based on this MALDI-TOF-based assay would also try to monitor the enzymatic activity at $\mathrm{Q}^{366}$. A different proteolytic digest from chymotrypsin must be used in order to isolate a $\mathrm{Q}^{366}$. This data would provide a basis of comparison between the two reactive glutamines. Additionally, $\alpha \mathrm{C}(233-425)$ mutants could be expressed to even further selectively monitor the catalytic reaction at each glutamine. The first mutant of focus would be Q237N, Q366N. This new protein would only allow the $\mathrm{Q}^{328}$ residue to be susceptible to transglutamination by FXIIIa.

The intact $\alpha \mathrm{C}(233-425)$ was also introduced to the ${ }^{15} \mathrm{NH}_{4} \mathrm{Cl}$ in the presence of FXIIIIa to allow the protein to be isotopically labeled. The ${ }^{15} \mathrm{~N}$ is incorporated into the reactive glutamine side chain amide groups, allowing them to be specifically monitored using ${ }^{15} \mathrm{~N}$ HSQC NMR. In the 2D HSQC spectrum of the enzymatic reaction seen in Figure 17, there appear to be two sets of glutamine amide proton peaks. However, one of the pairs of peaks was not seen as the expected two, clear resonances. One of the peaks appears as two small peaks, rather than one larger one. This could potentially be explained by the $\mathrm{Q}^{237}$ residue, which previously was not seen to greatly participate in crosslinking. The two strong sets of peaks would likely be the 
resonances of the amide protons of the reactive $\mathrm{Q}^{328}$ and $\mathrm{Q}^{366}$, with the one extra peak being caused by mild $\mathrm{Q}^{237}$ activities. Future studies would be aimed at labeling the specific glutamine peaks in the ${ }^{15} \mathrm{~N}$ HSQC spectra in order to selectively monitor the enzymatic reaction at the residue of interest. Also, the $\alpha \mathrm{C}(233-425)$ could be expressed with ${ }^{15} \mathrm{~N}$ initially incorporated into the structure of the glutamines' side chain amides. In the presence of unlabeled $\mathrm{NH}_{4} \mathrm{Cl}, \mathrm{FXIIIa}$ would facilitate the removal of the isotopic nitrogen. This reaction could be monitored using a similar ${ }^{15} \mathrm{~N}$ HSQC experiment in a time dependent fashion. 


\section{Conclusion}

From the experimental data, FXIIIa displayed varying substrate specificity towards the various model peptides. $\mathrm{K} 9(1-10)$ and $\alpha_{2} \mathrm{AP}(\mathrm{Q} 4)$ (1-15) proved to be viable substrates of the enzymatic transglutamination reaction, with K9 showing the greatest affinity. The $S$. aureus Fnb A (100-114) peptide favored undergoing a distinct isotopic reaction with ${ }^{15} \mathrm{NH}_{4}$, rather than the anticipated FXIIIa reaction. This newly proposed interaction between reactive glutamine and neighboring arginine residues of the peptide and the small lysine mimic appeared to be so favorable that no enzymatic activity was observed in the presence of FXIIIa. The cause of this substrate sequence specificity seems to come from the residues that are directly adjacent to the reactive glutamine. The $S$. aureus Fnb A and $\alpha_{2} \mathrm{AP}(\mathrm{Q} 4 \mathrm{P})$ peptides both have residues containing $\mathrm{sp}^{2}$ hybridized side chain carbons in arginine and glutamate, respectively, besides the reactive glutamine. This hybridization quality could allow an environment for the oxyanion of the amidate to be stabilized, as in the proposed mechanism. The arginine residue of $S$. aureus Fnb A (100-114) appears to undergo this reaction with greater ease than the glutamate of $\alpha_{2} A P(Q 4 P)$ (1-15), as the latter peptide functioned as a FXIIIa substrate. In contrast, K9 (1-10) has its reactive glutamine flanked by glycine and serine residues, both of which only have $\mathrm{sp}^{3}$ hybridized side chain carbons. This environment appears to not favor the nonenzymatic isotopic exchange, allowing for greater FXIIIa activity.

Additionally, the intact $\alpha \mathrm{C}(233-425)$ protein was seen to be a target of FXIIIa's transglutaminase activity. $\mathrm{Q}^{328}$ was observed to react with the enzyme in a linear fashion with time; however, because of low protein concentrations beneath the $\mathrm{K}_{\mathrm{m}}$ value of FXIIIa, the maximum velocity could not be reached. $\alpha \mathrm{C}(233-425)$ was able to undergo transglutamination at multiple glutamine residues, two and potentially three. This work has provided insights into 
the function and sequence specificity of FXIIIa and therefore, further information that can contribute to the manipulation of the blood coagulation cascade. 


\section{Acknowledgments}

I would like to thank the fellow members of my lab, past and present, for all of the help and guidance that they have provide me over the past two years: Dr. Prakash Doiphode, Ms. Marina Malovichko, Dr. David Cleary and Dr. Ricky Woofter. I also would like to show my appreciation to $\mathrm{IMD}^{3}$ for funding my work during the summer of 2012 and to the entire Department of Chemistry faculty for their expertise and advice. A very large and gracious thank you is extended to Dr. Muriel Maurer. Her enduring patience, support and attention to details have allowed me to grow as a critical, scientific thinker, which are invaluable skills that I will use the rest of my life. 


\section{Appendix A}

Figure A.1: Structure of $S$. aureus

Fnb A (110-114) with labeled amino acids. pH 7
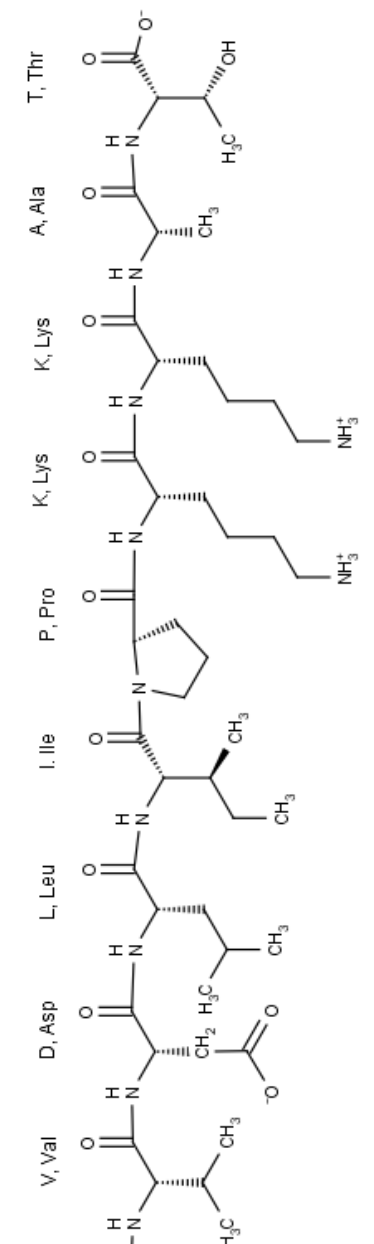

등

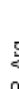

몬

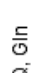

등
ㅁ$$
\text { 웅 }
$$

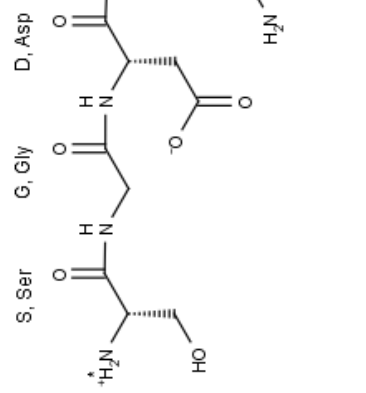




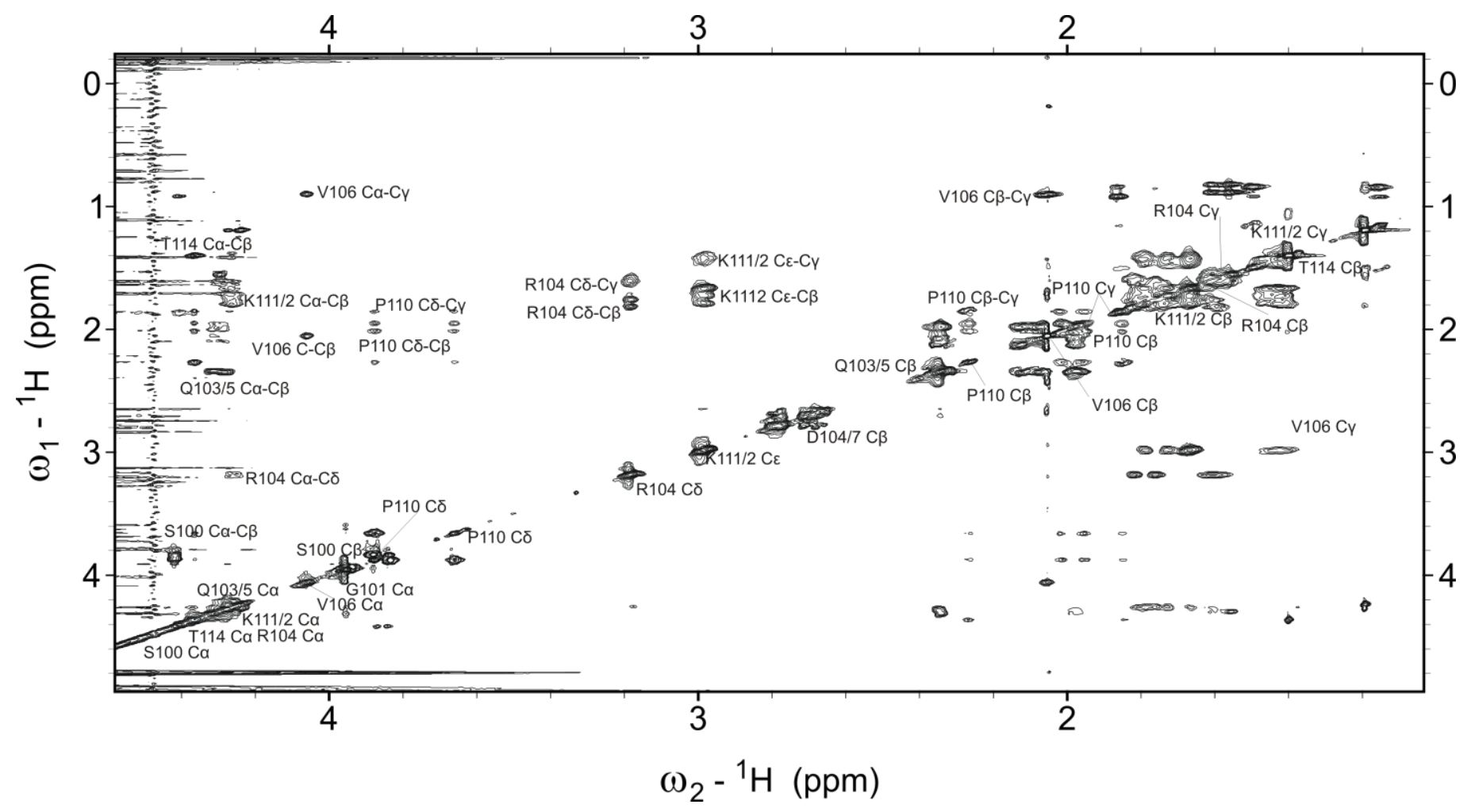

Figure A.2: 2 D TOCSY expansion of the aliphatic region of S. aureus FnbA (110-114) $\left({ }^{100}\right.$ SGDQRQVDLIPKKAT $\left.^{114}\right)$.

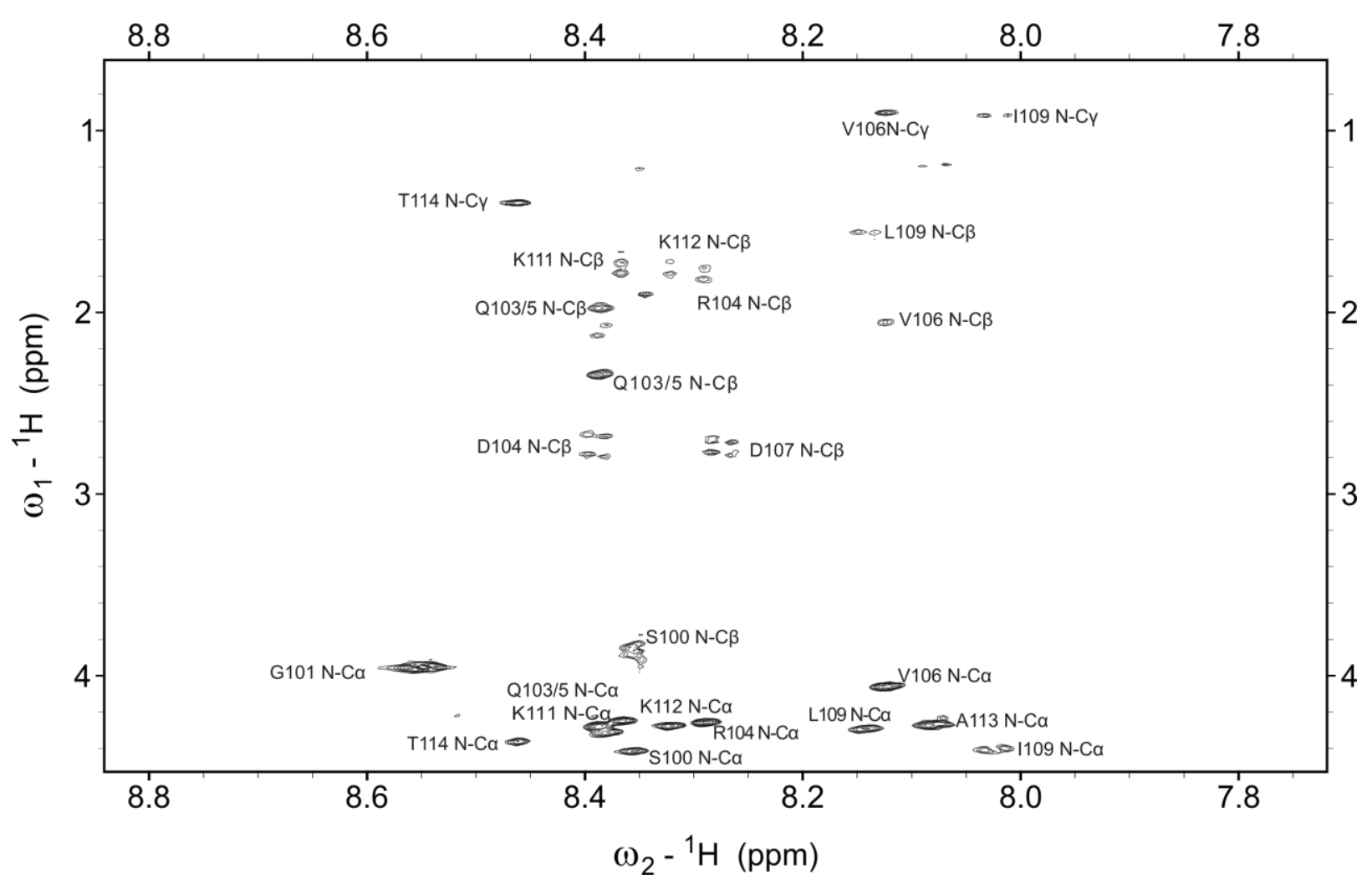

Figure A.3: 2D TOCSY expansion of the fingerprint region of S. aureus Fnb A (110-114) $\left({ }^{100}\right.$ SGDQRQVDLIPKKAT $\left.^{114}\right)$. 


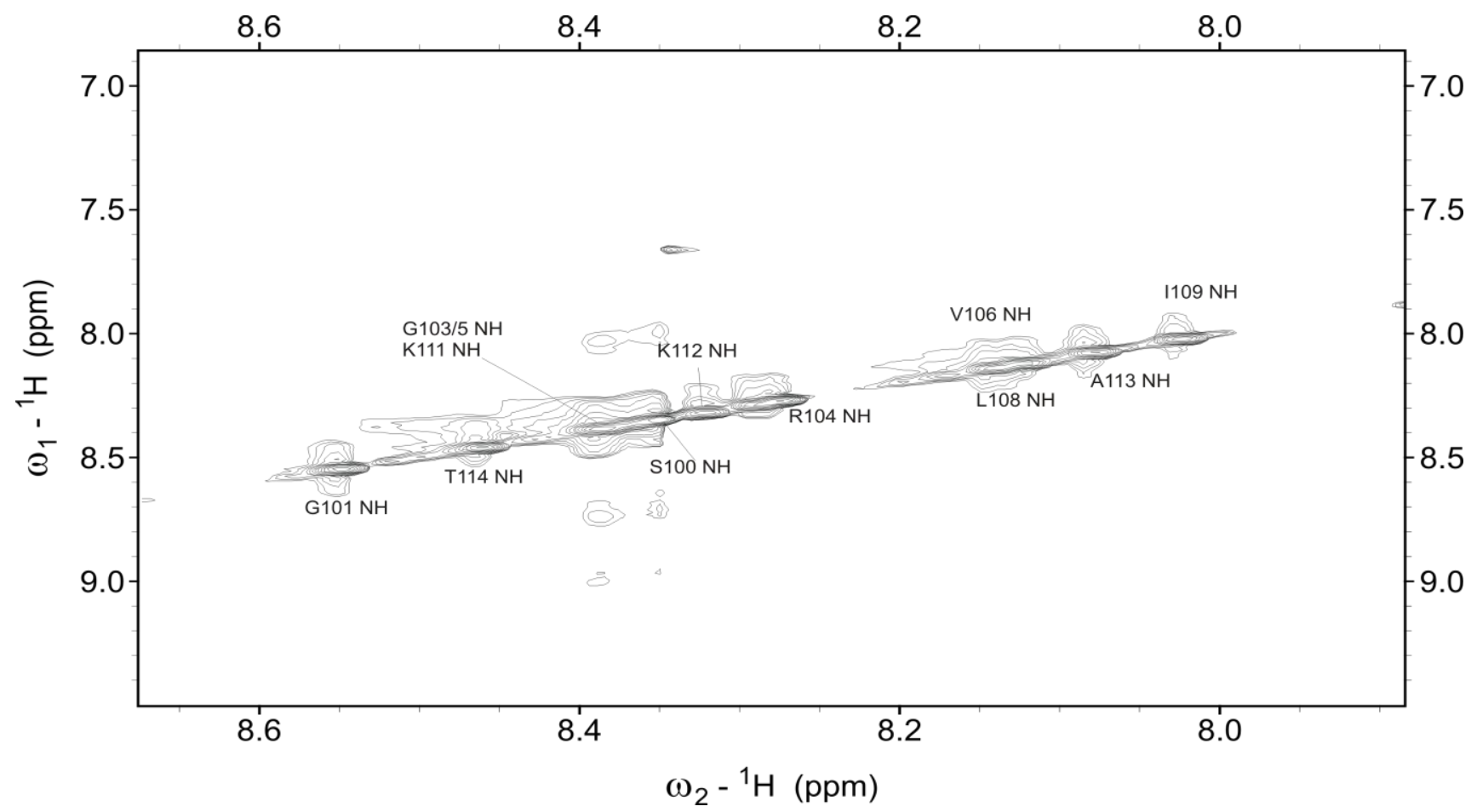

Figure A.4: 2 D TOCSY expansion of the amide backbone region of S. aureus Fnb A (100-114) $\left({ }^{100}\right.$ SGDQRQVDLIPKKAT $\left.^{114}\right)$.

\begin{tabular}{|c|c|c|c|c|}
\hline \multicolumn{5}{|c|}{ Chemical Shift (ppm) } \\
\hline residue & $\mathrm{NH}$ & $\mathrm{C}^{\alpha} \mathrm{H}$ & $\mathrm{C}^{\beta} \mathrm{H}$ & Others \\
\hline $\mathrm{S} 100$ & 8.357 & 4.424 & 3.859 & $\mathrm{n} / \mathrm{a}$ \\
\hline G101 & 8.552 & 3.955 & $\mathrm{n} / \mathrm{a}$ & $\mathrm{n} / \mathrm{a}$ \\
\hline D102 & 8.4 & $\mathrm{n} / \mathrm{a}$ & $2.78,2.669$ & $\mathrm{n} / \mathrm{a}$ \\
\hline Q103 & 8.384 & 4.29 & $1.97,2.077$ & ү 2.341 \\
\hline R104 & 8.29 & 4.252 & $1.828,1.771$ & ү $1.618, \delta 2.992$ \\
\hline Q105 & 8.384 & 4.29 & $1.97,2.12$ & ү 2.341 \\
\hline V106 & 8.125 & 4.055 & 2.058 & ү 0.8992 \\
\hline D107 & 8.267 & $\mathrm{n} / \mathrm{a}$ & $2.769,2.696$ & $\mathrm{n} / \mathrm{a}$ \\
\hline L108 & 8.141 & 4.304 & 1.57 & $\delta 0.8932,0.8048$ \\
\hline 1109 & 8.033 & 4.414 & 1.838 & $\gamma .09231,0.8704$ \\
\hline P110 & $\mathrm{n} / \mathrm{a}$ & 4.36 & $2.264,2.032$ & $\gamma 1.965,1.866 ; \delta 3.881,3.66$ \\
\hline $\mathrm{K} 111$ & 8.368 & 4.252 & $1.785,1.728$ & $\gamma 1.445, \delta 1.675, \varepsilon 2.992$ \\
\hline $\mathrm{K} 112$ & 8.32 & 4.29 & $1.795,1.728$ & ү $1.445, \delta 1.675, \varepsilon 2.992$ \\
\hline A113 & 8.068 & 4.256 & 1.182 & $\mathrm{n} / \mathrm{a}$ \\
\hline T114 & 8.46 & 4.377 & $\mathrm{n} / \mathrm{a}$ & ү 1.394 \\
\hline
\end{tabular}

Table A.1: Summary of chemical shift assignments in ppm for $S$. aureus Fnb A(110-114). Experiments were performed at $25^{\circ} \mathrm{C}$. Samples were buffered in $20 \mathrm{mM}$ borate at $\mathrm{pH} 7.0,50 \mathrm{mM} \mathrm{CaCl}_{2}, 100 \mathrm{mM}^{15} \mathrm{NH}_{4}, 10 \% \mathrm{D}_{2} \mathrm{O}$. Peptide concentration was $200 \mu \mathrm{M}$. 
Figure A.5: Structure of $\alpha_{2} \mathrm{AP}(\mathrm{Q} 4 \mathrm{P})$ (1-15) with labeled amino acids. $\mathrm{pH} 7$

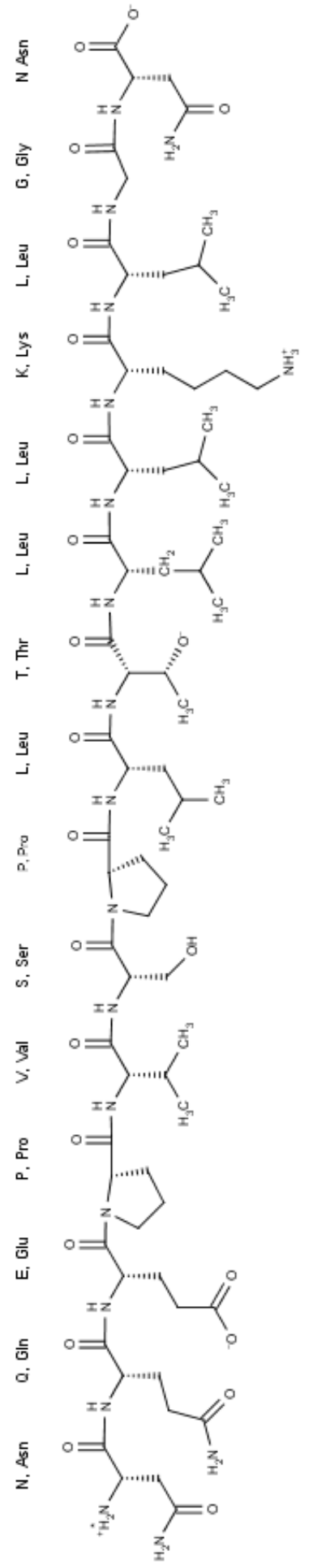




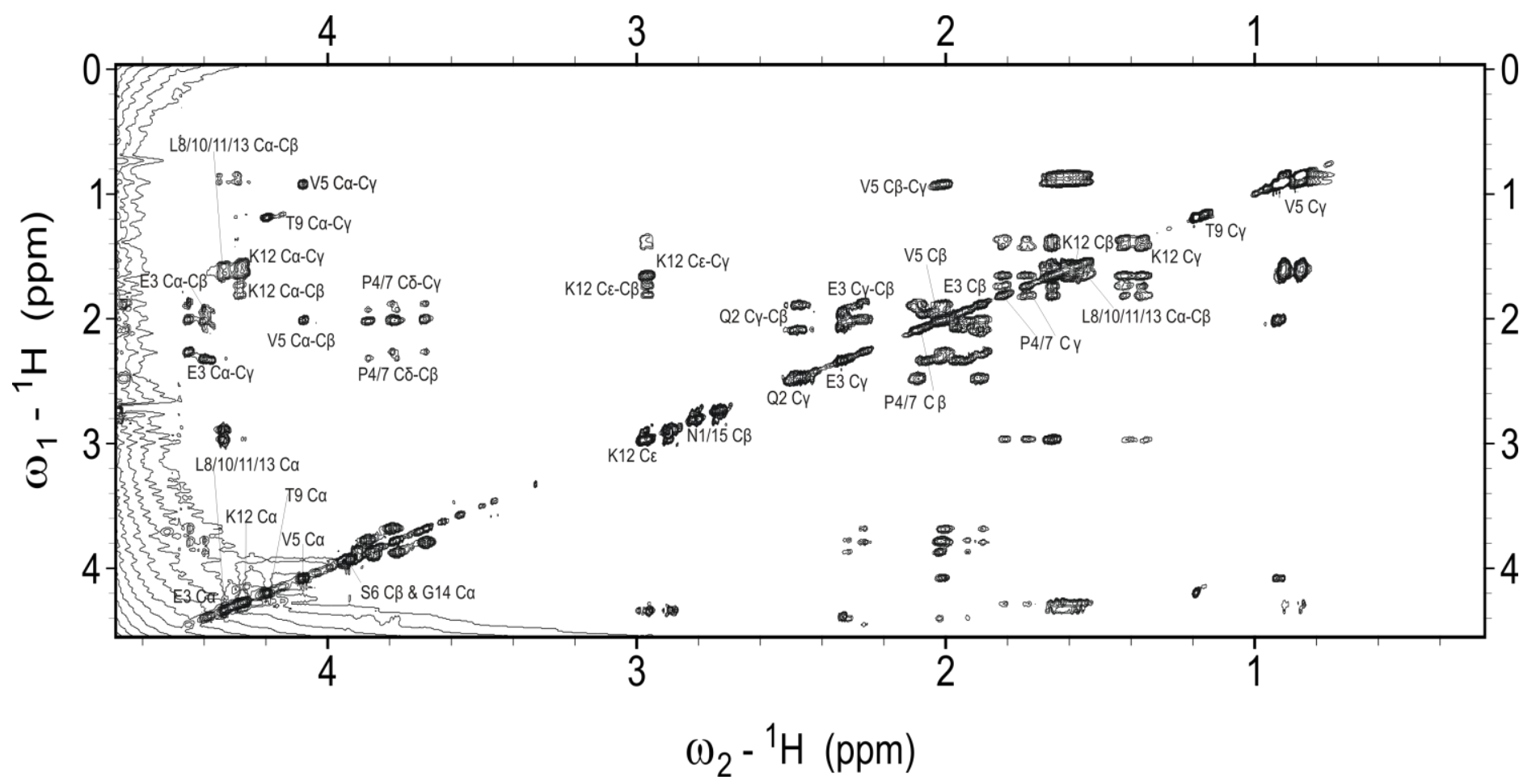

Figure A.6: $2 \mathrm{D}$ TOCSY expansion of the aliphatic region of $\alpha_{2} \mathrm{AP}(\mathrm{Q} 4 \mathrm{P})(1-14)\left({ }^{1} \mathrm{NQEPVSPLTLLKLGN}{ }^{15}\right)$.

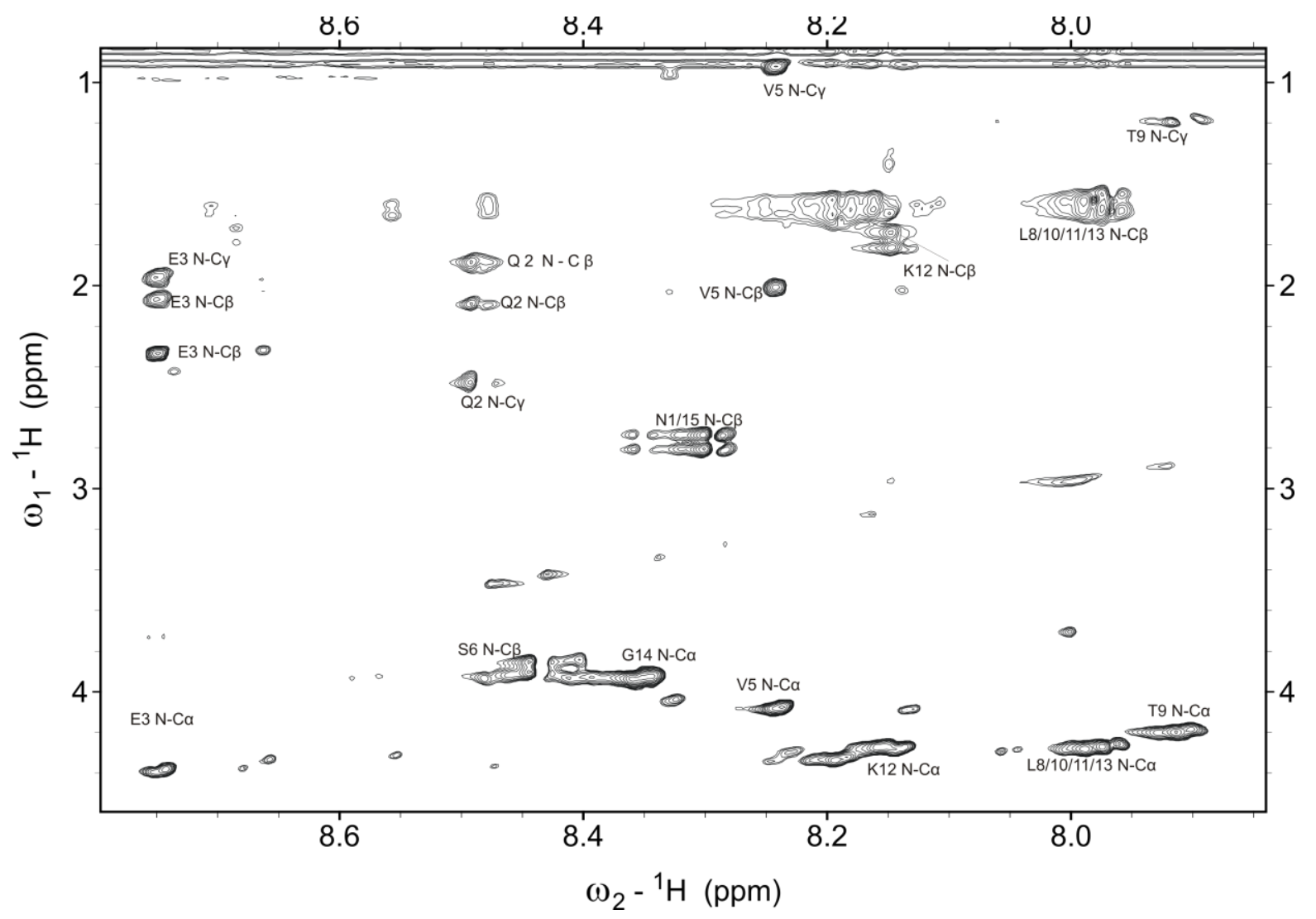

Figure A.7: $2 \mathrm{D}$ TOCSY expansion of the fingerprint region of $\alpha_{2} \mathrm{AP}(\mathrm{Q} 4 \mathrm{P})(1-14)\left({ }^{1} \mathrm{NQEPVSPLTLLKLGN}{ }^{15}\right)$. 


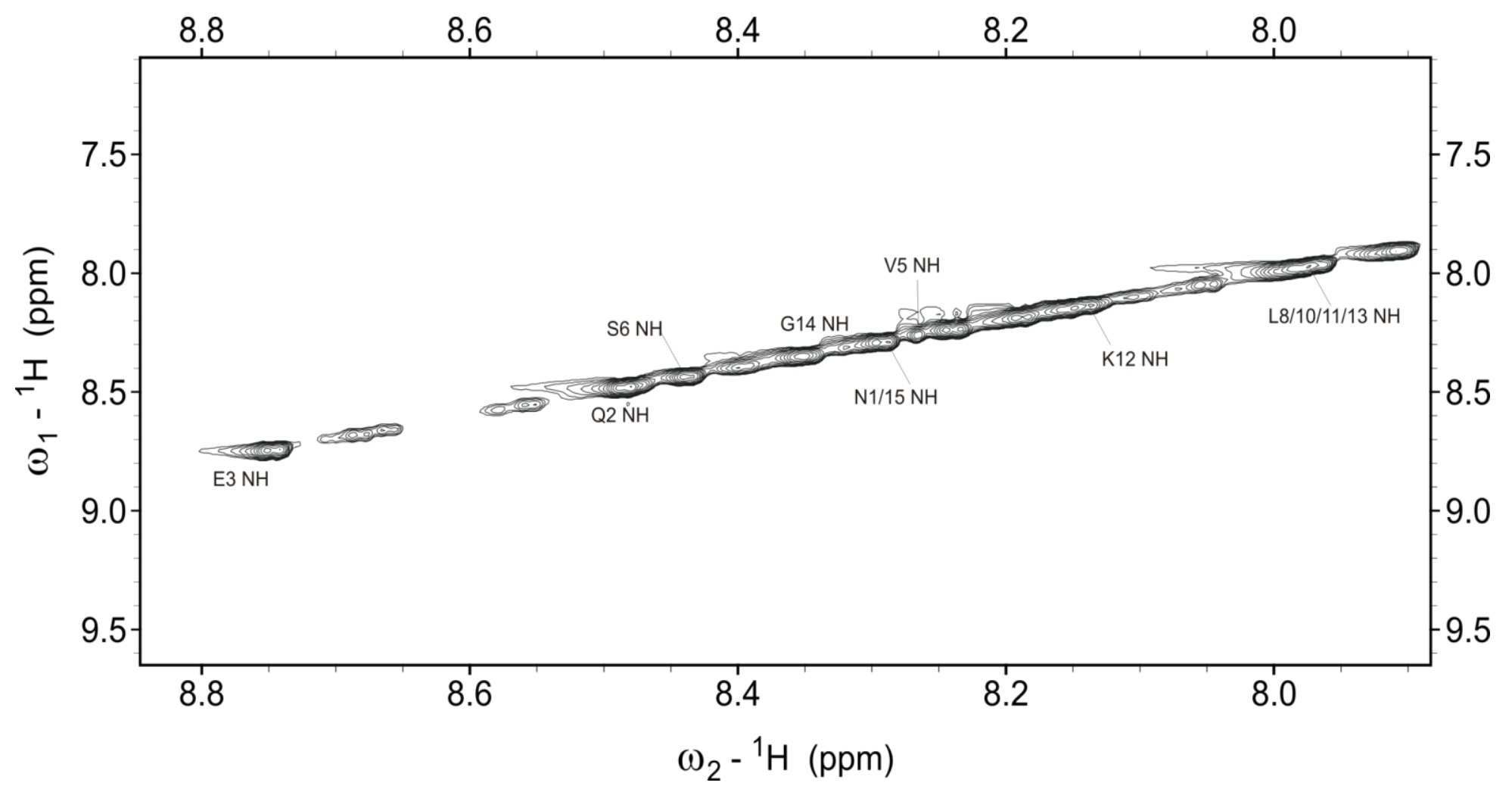

Figure A.8: 2D TOCSY expansion of the amide backbone region of $\alpha_{2} \mathrm{AP}(\mathrm{Q} 4 \mathrm{P})(1-14)\left({ }^{1} \mathrm{NQEPVSPLTLLKLGN}{ }^{15}\right)$.

\begin{tabular}{|c|c|c|c|c|}
\hline \multicolumn{5}{|c|}{ Chemical Shift (ppm) } \\
\hline residue & $\mathrm{NH}$ & $\mathrm{C}^{\alpha} \mathrm{H}$ & $\mathrm{C}^{\beta} \mathrm{H}$ & Others \\
\hline N1 & 8.303 & $\mathrm{n} / \mathrm{a}$ & $2.815,2.73$ & $\mathrm{n} / \mathrm{a}$ \\
\hline Q2 & 8.489 & $\mathrm{n} / \mathrm{a}$ & $2.096,1.893$ & ү 2.494 \\
\hline E3 & 8.747 & 4.404 & $2.079,1.978$ & V 2.35 \\
\hline P4 & $\mathrm{n} / \mathrm{a}$ & 4.396 & $2.318,2.091$ & ү 1.934; $\delta 3.87,3.788$ \\
\hline V5 & 8.24 & 4.083 & 2.012 & ү 0.9381 \\
\hline S6 & 8.443 & $\mathrm{n} / \mathrm{a}$ & 3.889 & $\mathrm{n} / \mathrm{a}$ \\
\hline P7 & $\mathrm{n} / \mathrm{a}$ & 4.396 & $2.267,2.012$ & ү $1.871 ; \delta 3.774,3.680$ \\
\hline L8 & 7.989 & 4.294 & $1.657,1.564$ & $\mathrm{n} / \mathrm{a}$ \\
\hline T9 & 7.914 & 4.193 & $\mathrm{n} / \mathrm{a}$ & $\vee 1.2$ \\
\hline L10 & 7.989 & 4.294 & $1.657,1.564$ & $\mathrm{n} / \mathrm{a}$ \\
\hline $\mathrm{L} 11$ & 7.974 & 4.269 & $1.657,1.564$ & $\mathrm{n} / \mathrm{a}$ \\
\hline $\mathrm{K} 12$ & 8.151 & 4.277 & $1.834,1.741$ & ү $1.414,1.365 ; \delta 1.805,1.756 ; \varepsilon 2.965$ \\
\hline $\mathrm{L} 13$ & 7.957 & 4.269 & $1.657,1.564$ & $\mathrm{n} / \mathrm{a}$ \\
\hline G14 & 8.344 & 3.922 & $\mathrm{n} / \mathrm{a}$ & $\mathrm{n} / \mathrm{a}$ \\
\hline N15 & 8.285 & $\mathrm{n} / \mathrm{a}$ & $2.815,2.73$ & $\mathrm{n} / \mathrm{a}$ \\
\hline
\end{tabular}

Table A.2: Summary of chemical shift assignments for $\alpha_{2} \mathrm{AP}(\mathrm{Q} 4 \mathrm{P})$ (1-14). Experiments were performed at $25^{\circ} \mathrm{C}$. Samples buffered in $20 \mathrm{mM}$ borate at $\mathrm{pH} 3.5,50 \mathrm{mM} \mathrm{CaCl}_{2}, 100 \mathrm{mM}^{15} \mathrm{NH}_{4}, 10 \% \mathrm{D}_{2} \mathrm{O}$. Peptide concentration was $200 \mu \mathrm{M}$. 


\section{References}

1. Fox, S. I. (2011). Human Physiology (12 ed.). New York: McGraw-Hill.

2. Standeven, D. F., Ariëns, R. A., \& Grant, P. J. (2005). The molecular physiology an pathology of fibrin structure/function. Blood Reviews , 275-288.

3. Cleary, D., \& Maurer, M. (2006). Characterizing the Specificity of Activated Factor XIIIfor Glutamine-Containing Substrate Peptides. Biochimica Et Biophysica Acta , 12071217.

4. Komaromi, I., Bagoly, Z., \& Muszebeck, L. (2011). Factor XIII: Novel Structural and Funcitonal Aspects. Journal of Thrombosis and Hemostasis , 9-20.

5. Ariëns, R., Lai, T., Weisel, J., Greenberg, C., \& Grant, P. (2002). Role of Factor XIII in Gibrin Clot Formation and Effections of Genetic Polymorphisms. BLOOD , 743-754.

6. Woofter, R. T. (2011). Conformational Dynamics Leading to Activation of the Transglutaminase Factor XIII. Dissertation, University of Louisville, Chemsitry, Louisville.

7. Severina, E., Nunez, L., Baker, S., \& Matsuka, Y. (2006). Factor XIIIa Mediated Attachment of S. aureus Fibronectin-Binding Protein A (Fbn A) to Fibrin: Identification of Gln 103 as a Major Cross-Linking Site. Biochemistry, 1870-1880.

8. Matsuka, Y., Anderson, E., Milner-Fish, T., Ooi, P., \& Baker, S. (2003). Staphylococcus, aureus Fibronectin-Binding Protein Serves as a Substrate for Coagulation of Factor XIIIa: Evidence of Factor XIIIa-Catalyzed Covalent Cross-Linking to Fibronectin and Fibrin. Biochemistry, 14643-14652.

9. Smith, K. A., Adamson, P. J., Pease, R. J., Brown, J. M., Balmforth, A. J., Cordell, P. A., et al. (2010). Interactions between Factor XIII and the alphaC Region of Fibrinogen. Blood, 3460-3468.

10. Shimba, N., Yokoyama, K., \& Suzuki, E. (2002). NMR-Based Screening Method for Transglutaminases: Rapid Analysis of Their Substrate Specificities and Reaction Rates. Journal of Agricultural and Food Chemistry, 1330-1334.

11. Doiphode, P. G. (2011). Sources of Factor XIII Specificiy: Kinetic Approaches for Deciphering the Glutamine Substrate Concensus Sequence. Doctorate of Philosophy Disertation, University of Louisville, Department of Chemistry, Louisville.

12. L. Sleno, D.A. Volmer, Rapid Commun Mass Spectrom 20 (2006) 1517-1524 